\title{
Schizophrenia-Like Features in Transgenic Mice Overexpressing Human HO-1 in the Astrocytic Compartment
}

\author{
Wei Song, ${ }^{1}$ Hillel Zukor, ${ }^{1,2}$ Shih-Hsiung Lin, ${ }^{1,2}$ Jacob Hascalovici, ${ }^{1,2}$ Adrienne Liberman, ${ }^{1}$ Ayda Tavitian, ${ }^{1,2}$ \\ Jeannie Mui, ${ }^{4}$ Hojatollah Vali, ${ }^{4,5}$ Xin-Kang Tong, ${ }^{3}$ Sanjeev K. Bhardwaj, ${ }^{6}$ Lalit K. Srivastava, ${ }^{6}$ Edith Hamel, ${ }^{2,3}$ \\ and Hyman M. Schipper ${ }^{1,2}$ \\ ${ }^{1}$ Lady Davis Institute, Jewish General Hospital, Montreal, Quebec H3T 1E2, Canada, ${ }^{2}$ Department of Neurology and Neurosurgery, McGill University, and \\ ${ }^{3}$ Laboratory of Cerebrovascular Research, Montreal Neurological Institute, Montreal, Quebec H3A 2B4, Canada, ${ }^{4}$ Facility for Electron Microscopy Research \\ and ${ }^{5}$ Department of Anatomy and Cell Biology, Faculty of Medicine, McGill University, Montreal, Quebec H3A 2B2, Canada, and ${ }^{6}$ Douglas Hospital and \\ Department of Psychiatry, McGill University, Montreal, Quebec H4H 1R3, Canada
}

Delineation of key molecules that act epigenetically to transduce diverse stressors into established patterns of disease would facilitate the advent of preventive and disease-modifying therapeutics for a host of neurological disorders. Herein, we demonstrate that selective overexpression of the stress protein heme oxygenase-1 (HO-1) in astrocytes of novel GFAP.HMOX1 transgenic mice results in subcortical oxidative stress and mitochondrial damage/autophagy; diminished neuronal reelin content (males); induction of Nurrl and Pitx3 with attendant suppression of their targeting miRNAs, 145 and 133b; increased tyrosine hydroxylase and $\alpha$-synuclein expression with downregulation of the targeting miR-7b of the latter; augmented dopamine and serotonin levels in basal ganglia; reduced $\mathrm{D}_{1}$ receptor binding in nucleus accumbens; axodendritic pathology and altered hippocampal cytoarchitectonics; impaired neurovascular coupling; attenuated prepulse inhibition (males); and hyperkinetic behavior. The GFAP.HMOX1 neurophenotype bears resemblances to human schizophrenia and other neurodevelopmental conditions and implicates glial HO-1 as a prime transducer of inimical (endogenous and environmental) influences on the development of monoaminergic circuitry. Containment of the glial HO-1 response to noxious stimuli at strategic points of the life cycle may afford novel opportunities for the effective management of human neurodevelopmental and neurodegenerative conditions.

\section{Introduction}

In various human neurodegenerative and neurodevelopmental disorders, a broad spectrum of risk and etiologic factors converge onto a restricted range of neuropathological and behavioral phenotypes. In the case of Alzheimer's disease (AD), indistinguishable neuropathological signatures accrue regardless of whether the degenerative process was fostered by genetic, traumatic, cardiovascular, metabolic, neuropsychological, or nutritional factors (Patterson et al., 2007). Similarly, various perinatal risk factors may "funnel" through limited neurodevelopmental pathways to engender schizophrenia and animal models thereof (Nitta et al., 2007; Brown, 2011).

Heme oxygenases $(\mathrm{HO})$ oxidize cellular heme to biliverdin, carbon monoxide (CO), and free ferrous iron. Biliverdin is fur-

\footnotetext{
Received Dec. 23, 2011; revised June 13, 2012; accepted June 18, 2012.

Author contributions: W.S. and H.M.S. designed research; W.S., H.Z., S.-H.L., J.H., A.L., A.T., J.M., X.-K.T., S.K.B., and E.H. performed research; W.S., H.Z., S.-H.L., A.L., A.T., H.V., L.K.S., and E.H. analyzed data; W.S. and H.M.S. wrote the paper.

This work was supported by Canadian Institutes of Health Research Grant MOP-68887 (H.M.S.) and The Mary Katz Claman Foundation (H.M.S.). W.S. is a senior scientist of The Mary Katz Claman Foundation. We thank Sara-Anne Arul for technical assistance with animal genotyping.

H.M.S. has served as consultant to Osta Biotechnologies, Molecular Biometrics, Inc., TEVA Neurosciences, and Caprion Pharmaceuticals. W.S., H.Z., S.-H.L., J.H., A.L., A.T., J.M., H.V., X.-K.T., S.K.B., L.K.S., and E.H. have no disclosures to declare. The authors declare no competing financial interests.

Correspondence should be addressed to Hyman M. Schipper, Lady Davis Institute, Jewish General Hospital, 3755 Côte Sainte Catherine Road, Montreal, Quebec H3T 1E2, Canada. E-mail: hyman.schipper@mcgill.ca.

DOI:10.1523/JNEUROSCI.6469-11.2012

Copyright $\odot 2012$ the authors $\quad 0270-6474 / 12 / 3210841-13 \$ 15.00 / 0$
}

ther catabolized to the bile pigment bilirubin by biliverdin reductase (Schipper et al., 2009a). Mammalian cells express an inducible isoform, HO-1, and constitutively active HO-2. Basal HO- 1 expression and activity are maintained at low levels in the normal brain and are restricted to neuroglia and small groups of scattered neurons (Schipper et al., 2009a). Numerous consensus sequences in the HMOX1 promoter render the gene exquisitely sensitive to induction by an array of prooxidant, inflammatory and other noxious stimuli implicated in AD, Parkinson's disease (PD), and schizophrenia (Schipper et al., 2009a; Brown, 2011). The heme oxygenase reaction may either confer cytoprotection by converting prooxidant heme and hemoproteins to the antioxidants biliverdin and bilirubin (Schipper et al., 2009a) or, conversely, liberate $\mathrm{CO}$ and ferrous iron, which may exacerbate oxidative stress within the mitochondrial and other cellular compartments (Zhang and Piantadosi, 1992; Schipper et al., 2009a). HO activity has been shown to afford neuroprotection (Panahian et al., 1999; Beschorner et al., 2000; Ahmad et al., 2006; Lin et al., 2007) or enhance vulnerability in various experimental models of neural injury and disease (Fernandez-Gonzalez et al., 2000; Wang and Doré, 2007; Yuan et al., 2008). HO-1 protein is overexpressed in astrocytes and decorates neuronal Lewy bodies in the substantia nigra of patients with PD (Schipper et al., 1998). In AD, HO-1 mRNA and protein are upregulated in astrocytes, neurons, and microvasculature of the hippocampus and cerebral cortex (Premkumar et al., 1995; Schipper et al., 2009a,b), and the pro- 
tein colocalizes to hallmark senile plaques, neurofibrillary tangles, granulovacuolar degeneration and neuropil threads (Smith et al., 1994; Schipper et al., 1995). HMOX1 is also induced in the prefrontal cortex of patients with schizophrenia (Prabakaran et al., 2004). In cultured astroglia, HO-1 upregulation by transient transfection of HMOX1 cDNA or stimulation of endogenous HO-1 expression by exposure to diverse stressors promotes intracellular oxidative stress, mitochondrial permeability transition, mitochondrial iron deposition (Schipper, 1999; Song et al., 2006), and macroautophagy (Zukor et al., 2009). In coculture paradigms, glial HO-1 overexpression enhances the vulnerability of nearby neuronal constituents to oxidative insult (Frankel and Schipper, 1999; Song et al., 2007). To ascertain directly whether this HO-1-mediated neuropathological cascade might prevail in the intact brain, novel GFAP.HMOX1 transgenic mice were engineered to allow conditional and selective expression of HMOX1 by the astrocytic compartment. The ensuing phenotype implicates glial HO-1 expression as a prime transducer of dystrophic stimuli in chronic neurological and psychiatric conditions.

\section{Materials and Methods}

\section{DNA constructs}

As illustrated (see Fig. $1 \mathrm{~A}$ ), the transgene cascade leads to activation of human (h) heme oxygenase-1 (HO-1) coding sequence through the upstream promoter drive of glial fibrillary acidic protein (GFAP) and the "valve controller" of tetracycline activator (tTA). This design confers two advantages: (1) The GFAP promoter selectively targets HMOX1 gene expression to the astrocytic compartment; (2) the tetracycline (Tet)-controllable ("Off") system permits temporal control of transgene expression. For this strategy, Tet-controllable pGFAP.tTA and pTRE2.Flag.HMOX1 constructs have been used to create the GFAP. HMOX1 transgenic (TG) mice. pTRE2.Flag.HMOX1 contains a fusion gene of Flag (F) (30 bp; derived from pcDNA3.1/Zeo.Flag) and the entire protein-coding sequence ( $866 \mathrm{bp}$ ) of HMOX1 (Song et al., 2006) under the minimal CMV promoter/enhancer. Through several steps of $p f u$ DNA polymerase-catalyzed PCR and subcloning, the Flag.HMOX1 fragment was inserted into pTRE2 (Clontech), downstream of the tetracycline-responsive element (TRE) and the minimal CMV promoter/ enhancer using a forward primer (5' $5^{\prime}$ CGC TGA GGA TCC ATG GAC TAC AAA GAC GAT-3') containing a BamHI site and a reverse primer (5' -CGT GCA TCT AGA TCA CAT GGC ATA AAG CCC-3') containing a HindIII site. For construction of pGFAP.tTA, the coding sequence of tTA containing the wild-type (WT) VP16 domain (allows high expression of tTA) derived from modified pUHD15-1 neo (courtesy of Dr. R. T. Lin, Lady Davis Institute for Medical Research, Montreal, Quebec, Canada) was subcloned into pDRIVE02-GFAP(h)04 (InvivoGen) under the GFAP promoter through several steps of $p f u$ DNA polymerase-catalyzed PCR and subcloning using a forward primer (5'-CGG CTC ATG ATG TCT AGA TTA GA-3') containing a BspHI site and a reverse primer (5'-AAT TAG AAT TCT CGC GCC CCC TA- $3^{\prime}$ ) containing a EcoRI site. DNA construct sequences and orientations were confirmed by (1) restriction enzyme analysis, (2) DNA sequencing, and (3) protein expression profiling using anti-Flag immunolabeling (Sigma-Aldrich) after in vitro transfection of primary rat astrocytes and HEK293 with pGFAP.tTA and/or pTRE2.Flag.HMOX1.

\section{Generation of TG mice}

A $2.6 \mathrm{~kb}$ XhoI-AseI DNA fragment from pTRE.Flag.HMOX1 containing a $\beta$-globin poly(A) sequence and a $3 \mathrm{~kb}$ PacI-PacI DNA fragment containing a SV40 poly(A) sequence from pGFAP.tTA were isolated, purified, and injected into pronuclei of fertilized FVB mouse eggs (McIntyre Transgenic Core Facility, McGill University, Montreal, Quebec, Canada) to generate two strains of transgenic mice harboring TRE.Flag.HMOX1 and GFAP.tTA, respectively. Transgenic mice expressing GFAP.tTA and TRE.Flag.HMOX1 mice were bred to produce GFAP.tTA.TRE.Flag. HMOX1 animals. To inhibit transgene expression, doxycycline (Dox) is provided in the diet $(200 \mathrm{mg} / \mathrm{kg}$, sterile; Bio-Serv) to breeding pairs and derived litters. To initiate transgene expression, the Dox diet was replaced with regular rodent diet.

\section{PCR genotyping}

Crude extracts containing genomic DNA from tail biopsy specimens were recovered using the REDExtract-N-Amp Tissue PCR kit (SigmaAldrich). The tTA coding sequence ( $1.009 \mathrm{~kb}$ fragment) was amplified with the primer pair as described above. The Flag + HMOX1 gene segment was amplified with pTRE2 sequence primer (5'-CGC CTG GAG ACG CCA TC-3') (forward), beginning at the lower part of the miniCMV sequence upstream of Flag.HMOX1, and Flag.HMOX1 subcloning primer (reverse) as described above, which amplified a $989 \mathrm{bp}$ fragment. The primers for GAPDH (glyceraldehyde 3-phosphate dehydrogenase) (Preisig-Müller et al., 1999) were used as an internal control to amplify a shorter fragment of $385 \mathrm{bp}$. Amplifications were performed in a total volume of $20 \mu \mathrm{l}$ containing $10 \mu \mathrm{l}$ of REDExtract-N-Amp PCR mix, $6 \mu \mathrm{l}$ of a mixture of each primer and PCR grade water, and $4 \mu \mathrm{l}$ of mouse tail extract as template. The PCR protocol consisted of an initial step of $3 \mathrm{~min}$ at $94^{\circ} \mathrm{C}$, followed by 35 cycles of $30 \mathrm{~s}$ at $94^{\circ} \mathrm{C}, 1 \mathrm{~min}$ at $57^{\circ} \mathrm{C}$, and $1 \mathrm{~min}$ at $72^{\circ} \mathrm{C}$. The final extension cycle was $10 \mathrm{~min}$ at $72^{\circ} \mathrm{C}$. To identify zygosities, genomic DNA was purified from mouse tails with a protease digestion protocol (Gains et al., 2006) and used to run quantitative PCR with PerfeCTa SYBR Green FastMix, Low ROX (Quanta Biosciences) according to the manufacturer's manual. Backcross breeding with WT mice was also used to confirm homozygosity.

\section{Animal husbandry}

The colony of FVB mice used to generate transgenic and WT animals originated from Harlan Laboratories. Experimental protocols pertaining to the use of mice in this study have been approved by the Animal Care Committee of McGill University in accordance with the guidelines of the Canadian Council on Animal Care. Mice were kept at a room temperature of $21 \pm 1^{\circ} \mathrm{C}$ with a $12 \mathrm{~h} \mathrm{light/dark} \mathrm{schedule.} \mathrm{All} \mathrm{the} \mathrm{mice} \mathrm{were} \mathrm{bred}$ and cared for in the Animal Care Facilities at the Lady Davis Institute for Medical Research. Fur texture, body weight, and survival rates were monitored as indices of general health. The transgenic mice used in all experiments were heterozygous. The behavioral studies and brain reelin immunostaining were performed in male and female mice separately. Male mice were used for the analysis of cerebral blood flow. For all other experiments (biochemical, histochemical, molecular biological, and morphological), animals of either sex were used.

\section{Surgical procedures}

(1) For standard perfusion, mouse brains were fixed by transcardial perfusion as previously described (Fenton et al., 1998) with minor modifications. Briefly, the animals were deeply anesthetized with rodent mixture containing ketamine, xylazine, acepromazine, and saline and perfused with $200 \mathrm{ml}$ of ice-cold saline followed by $250 \mathrm{ml}$ of cold $4 \%$ paraformaldehyde in $0.1 \mathrm{M}$ PBS, $\mathrm{pH} 7.4$, for light-microscopic analysis, or cold $2.5 \%$ glutaraldehyde in $0.1 \mathrm{~m}$ sodium cacodylate buffer, $\mathrm{pH} 7.5$, containing $0.1 \% \mathrm{CaCl}_{2}$ for transmission electron microscopy (TEM). The brains were removed and immersed in the same fixatives for $24 \mathrm{~h}$ at $4^{\circ} \mathrm{C}$. For RNA and protein expression assays, mouse brains were frozen in dry ice immediately after transcardial perfusion with $200 \mathrm{ml}$ of ice-cold PBS and stored at $-80^{\circ} \mathrm{C}$. (2) For HPLC and autoradiography assays, animals were decapitated and brains were removed and frozen in 2-methylbutane at $-40^{\circ} \mathrm{C}$ and stored at $-80^{\circ} \mathrm{C}$ until use (Laplante et al., 2004).

\section{ELISA}

The following regions were dissected from frozen mouse brain on dry ice: striatum (STM), substantia nigra-ventral tegmental area (SN/VTA), amygdala (AMYG), prefrontal cortex (PFC), temporal cortex (TC), and hippocampus (HC). HO-1 (human) EIA kit and ImmunoSet HO-1 (mouse) ELISA development set were used to quantify exogenous (transgenic) or endogenous (mouse) HO-1 protein expression, respectively, according to manufacturer instructions (Enzo Life Sciences). As the two kits exhibited similar detection sensitivities (0.78-25 and 0.195-12.5 ng/ $\mathrm{ml}$, respectively) and no significant cross-reactivity, total HO-1 expression in transgenic mouse brains could be calculated from combined 
assays. An indirect ELISA assay for nurr1 or pitx3 was assembled according to the protocols from Abcam (www.abcam.com/protocols). Briefly, $50 \mu \mathrm{l}(20 \mu \mathrm{g})$ of brain nucleus extraction lysate was uploaded to each well and incubated overnight at $4^{\circ} \mathrm{C}$ followed by a $2 \mathrm{~h}$ incubation with $100 \mu \mathrm{l}$ of blocking solution (10 mm sodium phosphate, $15 \mathrm{~mm} \mathrm{NaCl}, 1 \% \mathrm{BSA}$, $\mathrm{pH}$ 7.4) at room temperature. One hundred microliters of anti-Nurr1 or Pitx3 (Abgent) in blocking solution (1:1000) were added to each well and incubated for $2 \mathrm{~h}$ at room temperature. Each well was incubated with 100 $\mu l$ of HRP-conjugated secondary antibody (GE Healthcare) in blocking solution (1:500) for $1 \mathrm{~h}$ at room temperature. The washing, detection [using TMB $\left(3,3^{\prime}, 5,5^{\prime}\right.$-tetramethylbenzidine)], and stop solutions were the same as those of the HO-1 (human) EIA kit. The percentage changes of detected proteins in TG versus WT mice were analyzed using paired Student's $t$ test.

\section{mRNA and miRNA expression}

Total RNA extraction, polyadenylation, and cDNA synthesis. Total RNA from each dissected brain region was extracted in Trizol according to the manufacturer's instructions (Invitrogen). Five micrograms of total RNA were subjected to RT-PCR using Transcriptor First-Strand cDNA Synthesis Kit (Roche Diagnostics) and anchored-oligo- $\mathrm{dT}_{18}$ or random hexamer primer, and the resulting cDNA was amplified by PCR (Song et al., 2009). miRNA polyadenylation was performed followed by cDNA synthesis using $2.5 \mu \mathrm{g}$ of polyadenylated total RNA with NCode miRNA First-Strand cDNA Synthesis Kit (Invitrogen).

$m R N A$ and miRNA $q R T-P C R$. The Applied Biosystems 7500 Fast RealTime PCR System (Applied Biosystems by Life Technologies) was used to quantify mRNA and miRNA with SYBR GreenER SuperMix Universal (Invitrogen) according to manufacturer's instructions. Twenty-five nanograms of cDNA were quantified using the qRT-PCR Kit (Invitrogen) via real-time PCR. The forward and reverse primer sequences used to detect mRNA were designed with Primer Express Software, version 3.0 (Applied Biosystems by Life Technologies): (1) manganese superoxide dismutase (MnSOD): 5' -GCTGCACCACAGCAAGCA- $3^{\prime}$ and $5^{\prime}$-TCGG TGGCGTTGAGATTGT-3'; (2) Pitx3: 5'-AGGAATCGCTACCCTGAC ATGA- $3^{\prime}$ and $5^{\prime}$-ACGCGGGCCTCAGTGA-3'; (3) Nurr1: $5^{\prime}$-ATCCGG GCTCCCTTCACA-3' and 5'-TCTGCTCGATCATATGCGTAGTG-3'; (4) dopamine transporter (DAT): 5'-TGGAGTGCAGCTGACCAA CT-3' and 5'-GGTCTCCCGCTCTTGAACCT-3'; (5) tyrosine hydroxylase (TH): $5^{\prime}$-CGAGCTGCTGGGACACGTA-3' and 5'-CTGGGAGA ACTGGGCAAATG- $3^{\prime} ;(6) \alpha$-Synuclein:5'-GAAGGACCAGATGGGCAA G-3' and 5'-TTCCAGGATTCCTTCCTGTG-3'; (7) Beclin-1 (Becn1): 5' GGACAAGCTCAAGAAAACCAATG- 3 ' and $5^{\prime}$-TGTCCGCTGTGCCAGA TGT-3'; (8) lysosomal-associated membrane protein 2 (Lamp2): 5' -TGTG CCTCTCTCCGGTTAAAG- ${ }^{\prime}$ ' and $5^{\prime}$-CGGCTCCTAGGAACAGAAAGAT C-3'; (9) Sirtuin 1 (Sirt1): 5'-CCGCGGATAGGTCCATATACTT-3' and $5^{\prime}$-TCGAGGATCGGTGCCAAT- ${ }^{\prime}$. As an internal reference, $\beta$-Actin mRNA was used and probed using a pair of primers ( $5^{\prime}$-CAGCAGATGTGG ATCAGCAAG-3' and 5'-GCATTTGCGGTGGACGAT-3') (Mak et al., 2009). Mature DNA sense sequences (obtained from miRBase; http:// microrna.sanger.ac.uk/) were used as forward primers to detect miRNA. The miRNA primer sequences used were mmu-miR-133b (5'-tttggtcccc ttcaaccagcta- $\left.3^{\prime}\right)$, mmu-miR-145 (5'-gtccagttttcccaggaatccct- $\left.3^{\prime}\right)$, mmumiR-7a ( $5^{\prime}$-tggaagactagtgattttgttgt- $\left.3^{\prime}\right)$, and mmu-miR-7b (5' -tggaagactt gtgattttgttgt- $\left.3^{\prime}\right)$. As a reference sequence, $5 S$ rRNA was probed using an internal forward primer $\left(5^{\prime}\right.$-cagggtcgggccgttagtacttg- $\left.3^{\prime}\right)$. miRNA expression fold changes between groups were calculated using the $\Delta \Delta \mathrm{Ct}$ method relative to controls following normalization with levels of $5 \mathrm{~S}$ rRNA (Livak and Schmittgen, 2001).

\section{Histochemistry/immunohistochemistry}

Coronal brain sections $(40 \mu \mathrm{m})$ were cut on a Lancer vibratome (series 1000) (Lancer). For histochemistry, sections were stained with Gallyas suppressed silver, hematoxylin and eosin (H\&E), and Luxol fast blue. Immunohistochemistry (IHC) was performed with the Vectastain Elite $\mathrm{ABC}$ kit for mouse IgG (Vector Laboratories) using anti-Flag $\mathrm{mAb}$ (Sigma-Aldrich). For immunofluorescence (IF), sections were incubated with anti-Flag (Sigma-Aldrich), anti-S-100 $\beta$ (Sigma-Aldrich), and anti-TH mAbs (Millipore Bioscience Research Reagents), respectively, followed by donkey anti-mouse Cy3-labeled IgG (Jackson ImmunoResearch). After washing, the slides were incubated with anti-HO-1 (rabbit) (Enzo Life Sciences) or anti-MnSOD (sheep) pAb (Biodesign International) followed by goat anti-rabbit or anti-sheep FITC-labeled IgG (Vector Laboratories). For costaining of $\alpha$-synuclein and HO-1, sections were incubated with anti- $\alpha$-synuclein $\mathrm{mAb}$ (BD Biosciences Transduction Laboratories) followed by goat anti-mouse FITC-labeled IgG (Jackson ImmunoResearch). After washing, the slides were incubated with antiHO-1 (rabbit) pAb (Enzo Life Sciences) followed by goat anti-rabbit Cy2-labeled IgG (Jackson ImmunoResearch). Anti-reelin mAb (Calbiochem) and goat anti-mouse FITC-labeled IgG (Jackson Immuno Research) were used for reelin IF staining, with DAPI (4',6-diamidino2-phenylindole) $(1 \mu \mathrm{g} / \mathrm{ml})$ (Sigma-Aldrich) nuclear counterstaining. The histochemical and IHC preparations were examined using a Leica DM LB2 microscope. The IF sections were observed under a Carl Zeiss LSM 5 Pascal laser-scanning confocal imaging microscope.

\section{Western blot analyses}

Frozen mouse brains (48 weeks; off Dox) were subdissected into regions of interest. Brain tissue homogenates were prepared as whole-cell lysates according to procedures from Abcam (www.abcam.com/protocols) and crude membrane fractions by the method of Pérez-Otaño (http://sici. umh.es/Protocols.htm). Protein samples were boiled for $5 \mathrm{~min}$ in the presence of $6 \times$ SDS loading buffer before electrophoresis on precast 4-20\% SDS-PAGE (Thermo Fisher Scientific) and transferred to nitrocellulose membranes with $0.2 \mu \mathrm{m}$ pore size (Bio-Rad). Anti-LC3B rabbit $\mathrm{mAb}$ (Cell Signaling Technology) at 1:1000 and anti-rabbit IgG HRP (Promega) at 1:2500 were used to blot membranes. As an internal control, anti-actin clone C4 (Millipore Bioscience Research Reagents) at 1:5000 and anti-mouse IgG HRP (GE Healthcare) at 1:4000 were used to reblot minimally stripped membranes.

\section{Ultrastructural analyses}

Fixed mouse brains ( 48 weeks; off Dox) were subdissected into STM, HC, SN/VTA, and nucleus accumbens (NAcc) using an anatomic dissecting microscope and processed for TEM as previously described (Zukor et al., 2009).

\section{Behavioral tests}

GFAP.HMOX1 mice and their WT littermates at 48 weeks of age were transferred to the Neurophenotyping Centre of the Douglas Mental Health University Institute for behavioral analyses. The animals were tested for nonspatial memory (olfaction) (Wong and Brown, 2007), motor coordination and balance (rotarod) (Li et al., 2010), locomotor activity (Pinna et al., 2006), anxiety (Thatcher-Britton paradigm), and startle response [prepulse inhibition (PPI)] (Wood et al., 1998).

\section{Neurochemistry and dopamine receptor autoradiography}

The assays were performed on GFAP.HMOX1 mice (off Dox) and their WT littermates at 48 weeks of age.

HPLC. Brains were cut in 400-500 $\mu \mathrm{m}$ serial sections using a cryostat and selected brain regions (HC, AMYG, STM, NAcc, SN, and PFC) were dissected using 0.5-2.0 mm micropunches. Tissues were homogenized in 0.25 M perchloric acid and centrifuged at $4^{\circ} \mathrm{C}(10,000 \mathrm{rpm}, 15 \mathrm{~min})$, and supernatants were collected. The concentrations of monoamines [i.e., dopamine (DA), norepinephrine (NE), epinephrine (E), and 5-hydroxytryptamine (5HT)] and monoamine metabolites [i.e., 3,4-dihydroxyphenylacetic acid (DOPAC), homovanillic acid (HVA), and 5-hydroxyindoleacetic acid (5HIAA)], glutamate, and GABA were determined using HPLC with electrochemical detection (HPLC-EC), as previously described (Gratton et al., 1989).

Dopamine receptor autoradiography. Coronal brain sections $(20 \mu \mathrm{m})$ were cut at $-18^{\circ} \mathrm{C}$ on a cryostat, thaw-mounted on gelatin-coated slides, and stored at $-80^{\circ} \mathrm{C}$ for $\mathrm{D}_{1}$ and $\mathrm{D}_{2}$ receptor autoradiography as previously reported (Naef et al., 2008).

\section{Laser Doppler flowmetry}

Laser Doppler flowmetry measurement of cerebral blood flow (CBF) (Transonic Systems) was performed in 12-week-old TG and WT mice (off Dox) as described previously (Tong et al., 2009). 
Statistical analyses

Data are expressed as means \pm SEM. For locomotor activity, rotarod, and Thatcher-Britton paradigm, statistical analyses were performed in cases with more than two groups using a genotype (TG and WT) by treatment ( - Dox and +Dox) ANOVA followed by Newman-Keuls post hoc comparisons to assess significant main effects within groups. For PPI assessment of WT and TG mice (off Dox), two-way ANOVA was used to analyze serial intensity tests considering two factors (genotype and intensity). Fold changes in TG mice versus WT mice were analyzed with paired Student's $t$ test (two-tailed). Unless stated otherwise in the figure legends, all other comparisons were analyzed by one-way ANOVA followed by Newman-Keuls post hoc multiple-comparison test or by Student's $t$ test (two-tailed) where appropriate. Statistical significance was set at $p<0.05$.

\section{Results}

\section{General health of GFAP.HMOX1 mice}

GFAP.HMOX1 and WT mice did not differ with respect to fur texture, body weight, or mortality $(p>0.05$ for each comparison). At 48 weeks, complete blood count, plasma total and direct bilirubin, iron binding capacity, glucose, albumin, sodium, potassium, cholesterol, creatinine, and chlorine were similar between the groups ( $p>0.05$ for each comparison).

\section{HMOX1 transgene expression}

Immunoreactive Flag-tagged human $\mathrm{HO}-1$ protein appeared as homogeneous or punctate cytoplasmic staining in brain sections of TG mice, but was undetectable in WT littermates or TG mice on Dox, at embryonic day 12.5 (E12.5), 1 week (postnatal), 6 weeks (pubescent), and 48 weeks (Fig. $1 B, C$ ). Expression of the HMOX1 transgene was observed in astrocytes throughout the CNS including the STM, HC, AMYG, SN, VTA, NAcc, caudateputamen $(\mathrm{CPu}), \mathrm{PFC}$, and TC. The transgene was also expressed in ependymocytes and ependymal tanycytes (determined by morphology and anti-GFAP staining). hHO-1 immunoreactivity was not detected in oligodendroglia, microglia, neurons, or cerebrovascular cells; nor in heart, liver, spleen, lung, kidney, stomach, intestines, and gonads (data not shown). Total HO-1 protein expression in TG mouse brains was increased 1.36- to 5.76-fold compared with WT controls $[p<0.05-0.0001$ for the various regions, except for PFC $(p>0.05$; Fig. $1 F)]$. Transgenic HO-1 protein levels in the GFAP.HMOX1 mice were significantly greater in the SN/VTA than in the other brain regions surveyed $(p<0.05-0.001$; Fig. $1 D)$. Endogenous (mouse) HO-1 was unaffected or mildly decreased in some regions of the TG mouse brain relative to WT values (Fig. $1 E$ ).

\section{GFAP.HMOX1 mice exhibit hyperlocomotion and impaired prepulse inhibition}

Locomotor activity was significantly increased in TG mice at 48 weeks compared with WT controls and TG mice treated with Dox in an automated open-field test sampling horizontal activity $(p<$ $0.01)$, total distance $(p<0.05)$, movement number $(p<0.01)$, stereotypy count $(p<0.01)$, stereotypy number $(p<0.05)$, and stereotypy time $(p<0.05)$ (Table 1$)$. Locomotor abnormalities were not observed in 48-week-old TG mice exposed to Dox either continuously, until puberty (6 weeks), or from puberty until testing (data not shown). There were no significant differences between the groups in the Thatcher-Britton test (excluding anxiety as the cause of hyperlocomotion in the TG mice) and the rotarod test (motor coordination and balance) ( $p>0.05$ for each comparison). Prepulse inhibition, a sensorimotor gating abnormality frequently observed in human and experimental schizophrenia (Aasen et al., 2005), was significantly attenuated in male, but not female, TG mice at 48 weeks compared with WT controls (Fig. $2 A, B)$.

\section{Monoaminergic tone is augmented in the GFAP.HMOX1 brain}

In light of the observed behavioral abnormalities, we ascertained brain neurotransmitter concentrations with emphasis on the dopaminergic system (Table 2, Fig. 3). Relative to WT controls, TG mice exhibited significant elevations in the levels of DA in STM $(p=0.04)$ and SN $(p=0.02)$; DOPAC in STM $(p=0.02)$ with a trend in SN ( $p=0.091)$; and a trend for HVA in STM ( $p=$ 0.098). DOPAC/DA ratios, an index of neurotransmitter turnover rate, remained unchanged in the transgenic STM and SN relative to control values $(p>0.05)$. Levels of $\mathrm{NE}$ and $\mathrm{E}$ in the brains of WT and TG mice were similar for all regions surveyed $(p>0.05) .5$-HT and its metabolite, 5-HIAA, were significantly increased in the transgenic STM $(p=0.03$ and $p=0.004$ vs controls, respectively), but not in other regions $(p>0.05)$. No significant changes were observed in the levels of glutamate and GABA between the groups for all regions surveyed $(p>0.05)$. TG mice at 48 weeks exhibited a significant reduction in $D_{1}$ receptor $\left(D_{1} R\right.$ ) binding in NAcc compared with WT littermates (Fig. $3 A$ ). $\mathrm{D}_{1} \mathrm{R}$ binding in $\mathrm{CPu}$ and $\mathrm{SN}$, and $\mathrm{D}_{2} \mathrm{R}$ binding in all regions surveyed, did not differ between TG and WT animals (Fig. $3 A, B$ ).

\section{Catecholaminergic system genes are upregulated in the GFAP.HMOX1 brain}

We next examined the central expression of gene that may be responsible for the pronounced hyperdopaminergia of the GFAP. HMOX1 brain. TH mRNA increased in the transgenic STM at 6 and 48 weeks of age relative to WT values $(p<0.05$ and $p<0.01$, respectively). TH mRNA was suppressed in the transgenic $\mathrm{SN} /$ VTA at 6 weeks $(p<0.01)$ but was augmented at 48 weeks $(p<$ 0.01 ) in comparison with WT values (Fig. $4 A$ ). DAT mRNA in the TG mice exhibited a trend toward higher levels in STM and reduced levels in SN/VTA at 6 weeks, and significantly elevated levels in both regions at 48 weeks relative to WT values $(p<0.05)$ (Fig. 4A). On the basis of these findings, we hypothesized that Nurr 1 and Pitx3, transcription factors known to play vital roles in the development of central dopaminergic pathways, may be overexpressed in the GFAP.HMOX1 brain. We found that Nurr1 mRNA declined in the STM $(p<0.05)$ and remained unchanged in SN/VTA $(p>0.05)$ of TG mice at 6 weeks relative to WT controls (Fig. $4 B$ ). Conversely, Nurr1 was elevated in the TG SN/VTA $(p<0.05)$ and remained unchanged in STM $(p>0.05)$ at 48 weeks compared with WT littermates. Pitx3 mRNA was increased in the transgenic STM at 6 weeks $(p<0.01)$ and in both STM and SN/VTA at 48 weeks $(p<0.05$ and $p<0.001$, respectively) relative to WT littermates (Fig. $4 C$ ). In addition, both nurr 1 and pitx3 proteins (measured by ELISA) in the transgenic SN/VTA, but not STM, were significantly elevated at 48 weeks compared with WT littermates $(p<0.05)$. Pitx3 protein concentrations were below detection level in WT and TG STM, reflecting the fact that, unlike nurr 1, pitx3 elaboration remains restricted to mesencephalic DA neurons (Katunar et al., 2009) (Fig. 4D). Upon confirming the induction of Nurr1 and Pitx3 in the GFAP. HMOX1 brain at 48 weeks, we determined whether microRNAs (miRNAs) that suppress these transcription factors (i.e., miR-145 and miR-133b) may be underrepresented in the brains of these animals. In comparison with WT littermates, miRNA-145 (targeting Nurr1) was elevated in the transgenic STM at 6 weeks $(p<0.001)$ 
A

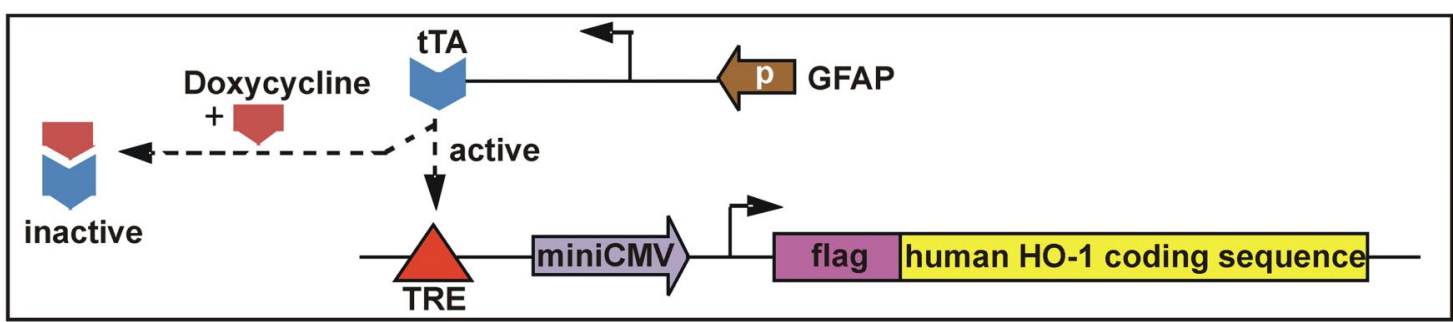

B

E12.5

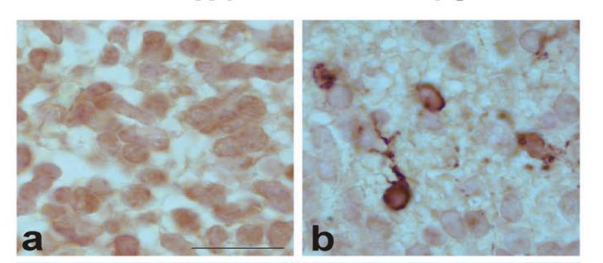

1 wk

6 wks

48 wks

D

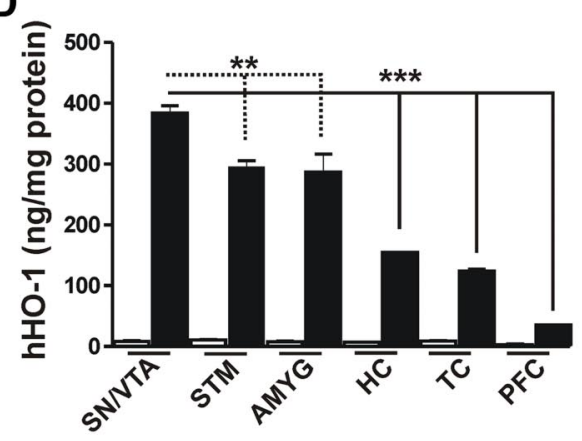

E



$\begin{array}{llll}\text { C } & \text { Flag } \square \quad \text { HO-1 } \square \quad \text { Merge } \square\end{array}$


WT 1 wk
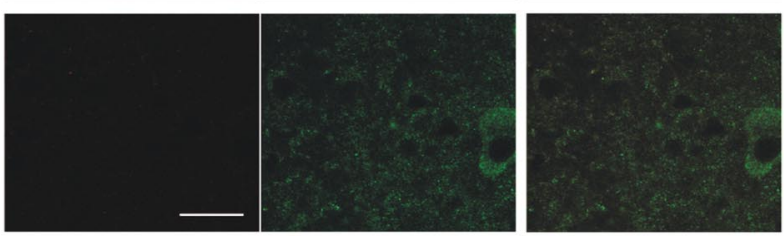

WT 6 wks
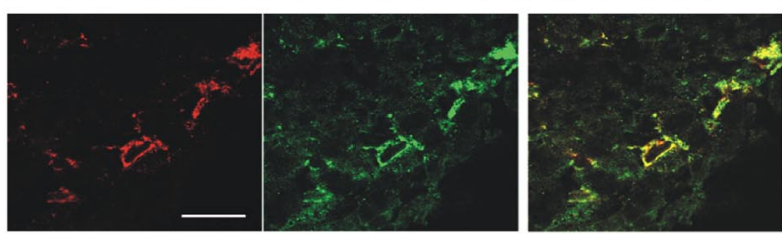

TG E12.5
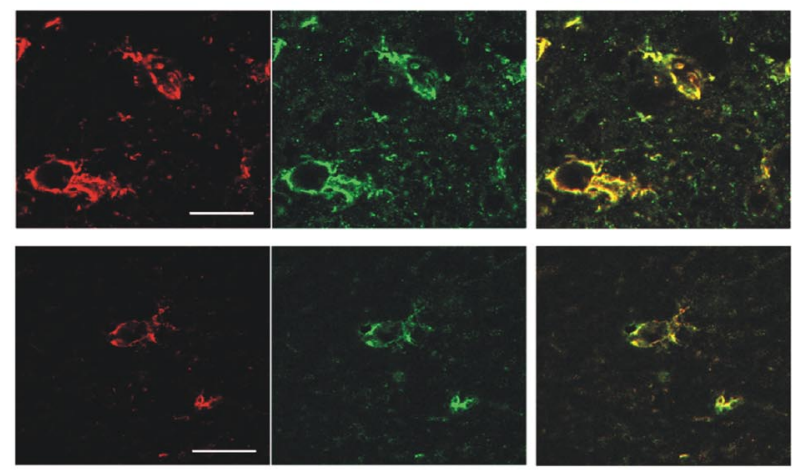

TG 6 wks
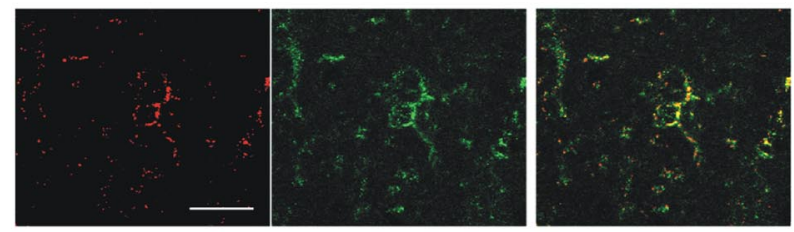

TG 48 wks
$\mathbf{F}$

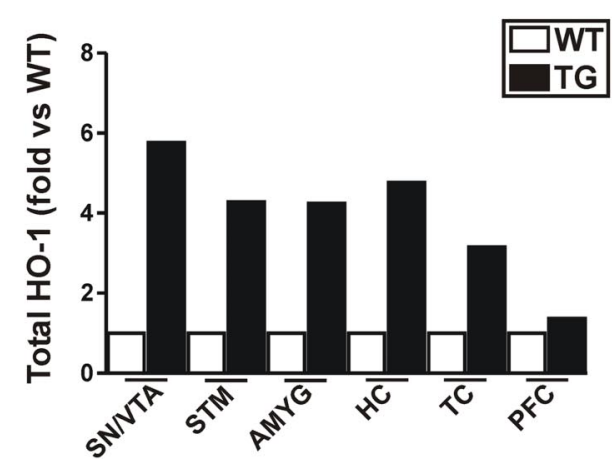

Figure 1. Construction of GFAP.HMOX1 transgenic mice. $A$, Schema of the tet-off regulatory system: tTA binds in absence of doxycycline, but not in its presence, to seven copies of the 42 bp tet operator sequence (tet0) and activates transcription of Flag-tagged human H0-1 gene from a minimal human cytomegalovirus promoter. Restricted expression in astroglia was (Figure legend continues.) 
Table 1. Behavior tests on WT and TG mice at 48 weeks of age

\begin{tabular}{|c|c|c|c|c|}
\hline Test (unit) & WT off Dox (n) & TG on Dox $(n)$ & TG off Dox $(n)$ & ANOVA \\
\hline Horizontal activity counts & $1624.66 \pm 140.83(13)$ & $1579.09 \pm 79.97(10)$ & $2341.20 \pm 176.34(9)^{\Delta * * 5 * *}$ & $p=0.001$ \\
\hline Total distance $(\mathrm{cm})$ & $395.27 \pm 48.79(13)$ & $377.83 \pm 44.86(10)$ & $615.54 \pm 73.29(9)^{\Delta * \delta * *}$ & $p=0.011$ \\
\hline Movement number & $81.69 \pm 7.23(13)$ & $85.42 \pm 4.76(10)$ & $117.15 \pm 7.03(9)^{\Delta * * \$ * *}$ & $p=0.002$ \\
\hline Stereotypy counts & $980.76 \pm 90.59(13)$ & $933.77 \pm 56.87(10)$ & $1447.98 \pm 120.42(9)^{\Delta * * \S * *}$ & $p=0.002$ \\
\hline Stereotypy number & $78.90 \pm 4.14(13)$ & $81.79 \pm 5(10)$ & $94.73 \pm 1.57(9)^{\Delta * \$ *}$ & $p=0.014$ \\
\hline Stereotypy time (s) & $122.45 \pm 10.17(13)$ & $117.90 \pm 6.73(10)$ & $164.91 \pm 14.89(9)^{\Delta_{*} \delta_{* *}}$ & $p=0.012$ \\
\hline Thatcher-Britton (s) & $324.27 \pm 47.28(11)$ & $295.11 \pm 56.05(9)$ & $317.89 \pm 59.91(9)$ & $p=0.926$ \\
\hline Olfactory (\% digging in CS ${ }^{+}$) & $82.51 \pm 2.01(10)$ & $84.99 \pm 1.35(9)$ & $84.60 \pm 1.88(9)$ & $p=0.654$ \\
\hline Rotarod-max speed (rpm) & $7.91 \pm 0.73 \sim 8.64 \pm 1.53(12)$ & $6.92 \pm 0.8 \sim 8.39 \pm 0.12(11)$ & $9.63 \pm 1.94 \sim 9.67 \pm 1.76(9)$ & $p=0.215$ \\
\hline
\end{tabular}

Behavior tests. Increased locomotion (horizontal activity, total distance, movement number, stereotypy count, stereotypy number, stereotypy time) was observed in TG mice off Dox relative to control littermates at 48 weeks of age. The latency to begin eating was recorded in the Thatcher-Britton paradigm. No significant differences were found between TG and WT mice for all rotarod subtests (i.e. maximum speed, time on rod, and total rotarod distance); maximum speed values are listed in the table. For the olfactory discrimination learning and memory task, the preference of trained mice for the positive conditional stimulus $\left(\mathrm{CS}^{+}\right)$was assessed with percentage digging around $\mathrm{CS}^{+}$as the dependent variable.

${ }^{*} p<0.05 ;{ }^{* *} p<0.01 ;{ }^{\Delta} \mathrm{TG}$ off Dox significant relative to TG on Dox; ${ }^{5} \mathrm{TG}$ off Dox significant relative to WT off Dox.
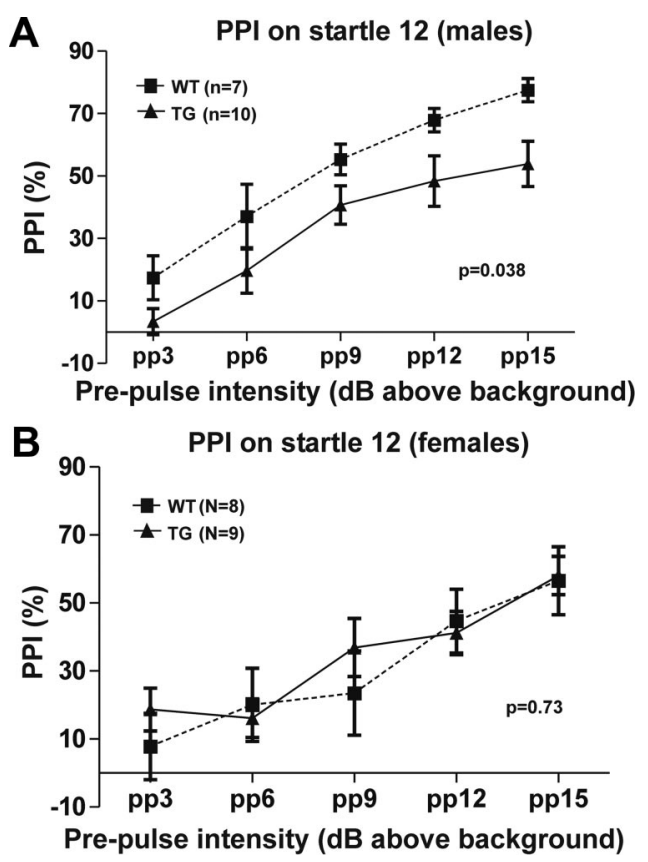

Figure 2. PPI.PPI was calculated by the following formula:PPI $=($ STARTLE - PPI)/STARTLE) $\times$ 100 , where STARTLE was the mean amplitude of 12 startle trials of the startle, and PPI was the mean from the trials at each of the different PP intensities (i.e., 3, 6, 9, 12, and $15 \mathrm{~dB}$ above background).

but was significantly suppressed in SN/VTA at 6 weeks and in STM at 48 weeks $(p<0.05)$ (Fig. $4 B)$. miRNA-133b (targeting Pitx3) declined at 6 weeks in both the transgenic STM and SN/VTA $(p<$ 0.01 ), with recovery to WT values by 48 weeks $(p>0.05)$ (Fig. $4 C)$.

\section{$\leftarrow$}

(Figure legend continued.) achieved by placing the tTA gene under the control of the astrocyte-specific GFAP promoter. $\boldsymbol{B}$, Anti-Flag immunohistochemistry of TG mice and WT control brains. Depicted are WT $(\boldsymbol{a}, \boldsymbol{c}, \boldsymbol{e}, \boldsymbol{g})$ and TG $(\boldsymbol{b}, \boldsymbol{c}, \boldsymbol{f}, \boldsymbol{h})$ mice at E12.5, and postnatal 1,6 , and 48 weeks. Flag-H0-1-positive cells were detected in TG $(\boldsymbol{b}, \boldsymbol{d}, \boldsymbol{f}, \boldsymbol{h})$, but not WT $(\boldsymbol{a}, \boldsymbol{c}, \boldsymbol{e}, \boldsymbol{g})$, brains. Scale bar: $\boldsymbol{a}-\boldsymbol{h}, 10 \mu \mathrm{m}$. C, Anti-Flag/Anti-H0-1 dual label immunofluorescence of TG and WT mouse brain. Depicted are WT at 1 and 6 weeks, and TG at E12.5 and 1, 6, and 48 weeks. Flag immunostaining appears red (left column), and H0-1 immunoreactivity appears green (middle column). Colocalization (yellow fluorescence) is demonstrated in the right column. Colocalization of $\mathrm{HO}-1$ and Flag-H0-1 was consistently observed in the TG mouse brain, whereas the WT brain was immunonegative for both proteins. Scale bars: TG 1 week, WT 6 weeks, $15 \mu \mathrm{m}$; TG E12.5, TG 6 weeks, TG 48 weeks, $20 \mu \mathrm{m}$; and WT 1 week, $50 \mu \mathrm{m}$. D, hH0-1 ELISA. Robust hH0-1 protein concentrations were observed in TG brains but not in age-matched WT preparations. $\boldsymbol{E}$, Endogenous mouse $\mathrm{H0}-1$ (mH0-1) protein levels were similar to or slightly below control values. $\boldsymbol{F}$, Fold change of total $\mathrm{H} 0-1$ in TG brains relative to WT levels. $n=4-6$ per group. ${ }^{*} p<$ $0.05 ;{ }^{* *} p<0.01 ;{ }^{* * *} p<0.001$. Error bars indicate SEM.

\section{Neuropathology of the GFAP.HMOX1 brain}

We anticipated neuropathology in the TG mice involving both the astrocytic and neuronal compartments because (1) hHO-1 transfection of rat astroglia promotes mitochondrial iron deposition and mitophagy (Schipper et al., 2009a), (2) coculture of neuron-like PC12 cells with HO-1-transfected astroglia sensitizes the former to oxidative injury (Frankel and Schipper, 1999; Song et al., 2007), and (3) GFAP.HMOX1 mice manifest overt behavioral abnormalities. All neuropathological evaluations were performed at 48 weeks of age commensurate with the behavioral and neurochemical analyses. H\&E staining (Fig. 5A) revealed altered hippocampal cytoarchitectonics in both male and female GFAP. HMOX1 mice characterized by diminished widths of the dorsal hippocampus ( $p<0.05-0.01$ vs WT), dysgenesis and shortening $(p<0.05-0.01$ vs WT) of the blades of the dentate gyrus, and reduced granule cell packing densities in the crest of the dentate gyrus (Fig. 5A). The TG mice exhibited no changes in Luxol fast blue (myelin) staining, GFAP and S-100 $\beta$ mRNA and protein levels, and $\beta$-amyloid or phospho-tau immunoreactivity (data not shown). Gallyas-positive (degenerate) neurites were abundant in the transgenic SN and were rarely seen in WT animals (Fig. 5B). Akin to earlier in vitro studies (Schipper et al., 2009a), in the transgenic SN and AMYG, astrocytic mitochondria were reduced in number, often distended (diameters of $0.75-1.25 \mu \mathrm{m}$ vs $0.5 \mu \mathrm{m}$ in control cells) and characterized by disorganized, damaged, or absent cristae, exaggerated intercristal spacing, diffuse or segmental membrane rupture, and foci of electron dense material. There were also abundant pleiomorphic, osmiophilic inclusions and lipofuscin granules, ultrastructural features of macroautophagy (Fig. $5 D, E$ ). Degenerate membranes ("myelin figures") were observed within neurites in close proximity to pathological astrocytes in TG, but not WT, preparations (Fig. 5E). Astrocytes in the TG brains also displayed frequent invaginations of the nuclear envelope rarely encountered in WT preparations (Fig. 5D).

MnSOD mRNA, a marker of oxidative stress that accumulates in cultured astrocytes under HO-1 provocation (Frankel et al., 2000), was significantly increased in the transgenic STM at 6 weeks $(p<0.05)$, but not in the SN/VTA. At 48 weeks of age, MnSOD mRNA levels were significantly elevated in both regions $(p<0.05$ and $p<0.001$, respectively) (Fig. $4 E)$. MnSOD protein immunofluorescence was augmented in the transgenic $\mathrm{SN}$ and STM at 48 weeks, with colocalization to hHO-1, S-100 $\beta$, and TH-positive cells denoting oxidative stress in both astroglial and neuronal (dopaminergic) compartments (Fig. 5C). The latter also prompted us to investigate the expression of $\alpha$-synuclein, a protein implicated in astrocytic and dopaminergic cell dysfunc- 
Table 2. Neurochemistry measurements on WT and TG mice at 48 weeks of age

\begin{tabular}{|c|c|c|c|c|c|c|}
\hline \multirow[b]{2}{*}{ NTs } & \multicolumn{6}{|c|}{ Brain regions (WT/TG) } \\
\hline & STM & SN & $\mathrm{HC}$ & AMYG & NAcc & PFC \\
\hline \multirow[t]{2}{*}{ DA } & $18.9 \pm 9.3$ & $10.7 \pm 7.2$ & $13.2 \pm 7.5$ & $34.4 \pm 10.5$ & $30.6 \pm 15.7$ & $6.0 \pm 1.9$ \\
\hline & $55.3 \pm 11.6^{*}$ & $54.0 \pm 12.4^{*}$ & $22.8 \pm 10.4$ & $36.9 \pm 16.8$ & $37.2 \pm 18.0$ & $3.4 \pm 0.4$ \\
\hline \multirow[t]{2}{*}{ DOPAC } & $9.3 \pm 4.9$ & $8.6 \pm 4.5$ & $14.7 \pm 10.3$ & $7.9 \pm 3.6$ & $26.9 \pm 18.1$ & $4.9 \pm 0.7$ \\
\hline & $29.5 \pm 5.3^{*}$ & $29.0 \pm 9.6^{\dagger \dagger}$ & $17.7 \pm 8.0$ & $16.2 \pm 6.9$ & $25.4 \pm 10.0$ & $3.9 \pm 0.6$ \\
\hline \multirow[t]{2}{*}{ HVA } & $81.1 \pm 21.9$ & $420.1 \pm 141.1$ & $203.0 \pm 57.3$ & $88.4 \pm 29.3$ & $114.9 \pm 31.0$ & $4.9 \pm 0.7$ \\
\hline & $143.3 \pm 24.1^{\dagger}$ & $324.8 \pm 105.7$ & $288.0 \pm 87.9$ & $113.9 \pm 50.4$ & $91.2 \pm 42.1$ & $3.9 \pm 0.6$ \\
\hline \multirow[t]{2}{*}{ DOPAC/DA } & $0.6 \pm 0.1$ & $0.5 \pm 0.1$ & $0.9 \pm 0.2$ & $0.6 \pm 0.3$ & $0.8 \pm 0.1$ & $0.3 \pm 0.1$ \\
\hline & $0.6 \pm 0.2$ & $0.6 \pm 0.2$ & $0.8 \pm 0.1$ & $0.5 \pm 0.1$ & $0.95 \pm 0.2$ & $0.2 \pm 0.01$ \\
\hline \multirow[t]{2}{*}{5 -HT } & $1.0 \pm 0.3$ & $3.5 \pm 1.1$ & $5.3 \pm 3.6$ & $1.8 \pm 3.6$ & $2.4 \pm 0.9$ & $4.8 \pm 0.6$ \\
\hline & $3.3 \pm 0.8^{*}$ & $3.9 \pm 1.0$ & $3.8 \pm 1.3$ & $1.9 \pm 0.7$ & $2.1 \pm 0.6$ & $3.9 \pm 0.7$ \\
\hline \multirow[t]{2}{*}{ HIAA } & $1.9 \pm 0.5$ & $6.6 \pm 2.3$ & $12.2 \pm 7.7$ & $2.0 \pm 0.7$ & $4.2 \pm 1.7$ & - \\
\hline & $4.7 \pm 0.6^{* *}$ & $9.5 \pm 3.9$ & $9.9 \pm 3.6$ & $2.1 \pm 0.5$ & $4.5 \pm 1.0$ & - \\
\hline \multirow[t]{2}{*}{ NE } & $2.2 \pm 0.4$ & $6.8 \pm 1.7$ & $4.3 \pm 1.1$ & $3.5 \pm 1.1$ & $4.7 \pm 1.1$ & $10.8 \pm 0.7$ \\
\hline & $3.0 \pm 0.6$ & $5.7 \pm 1.2$ & $8.3 \pm 2.5$ & $3.4 \pm 2.0$ & $2.6 \pm 0.5$ & $10.9 \pm 0.5$ \\
\hline \multirow[t]{2}{*}{$\mathrm{E}$} & $0.5 \pm 0.1$ & $1.8 \pm 0.6$ & $4.3 \pm 3.4$ & $1.8 \pm 0.9$ & $1.0 \pm 0.4$ & $3.4 \pm 0.3$ \\
\hline & $0.9 \pm 0.2$ & $1.9 \pm 0.6$ & $2.0 \pm 0.6$ & $1.8 \pm 0.9$ & $0.4 \pm 0.4$ & $4.3 \pm 0.5$ \\
\hline \multirow[t]{2}{*}{ GLU } & $55.8 \pm 15.3$ & $269.1 \pm 110.4$ & $69.0 \pm 13.6$ & $107.7 \pm 34.9$ & $91.9 \pm 20.3$ & $1763.3 \pm 251.6$ \\
\hline & $70.1 \pm 21.9$ & $96.2 \pm 25.2$ & $96.2 \pm 32.1$ & $97.1 \pm 62.7$ & $51.8 \pm 18.0$ & $2374.7 \pm 409.7$ \\
\hline \multirow[t]{2}{*}{ GABA } & $74.1 \pm 9.4$ & $363.5 \pm 83.8$ & $84.8 \pm 30.5$ & $87.8 \pm 21.5$ & $203.5 \pm 104.2$ & $243.3 \pm 41.3$ \\
\hline & $89.2 \pm 13.8$ & $222.0 \pm 74.5$ & $178.5 \pm 49.4$ & $76.6 \pm 36.1$ & $97.4 \pm 55.0$ & $253.8 \pm 44.9$ \\
\hline
\end{tabular}

Neurochemistry (HPLC-EC). The concentrations of neurotransmitters and their metabolites in various brain regions are listed and analyzed with unpaired Student's $t$ test. $n=5-6$ per group. Calculations are expressed as nanograms per milligram protein. NTs, Neurotransmitters.

${ }^{\dagger} p=0.098 ;{ }^{+\dagger} p=0.091 ;{ }^{*} p<0.05 ; * * 0.01$.

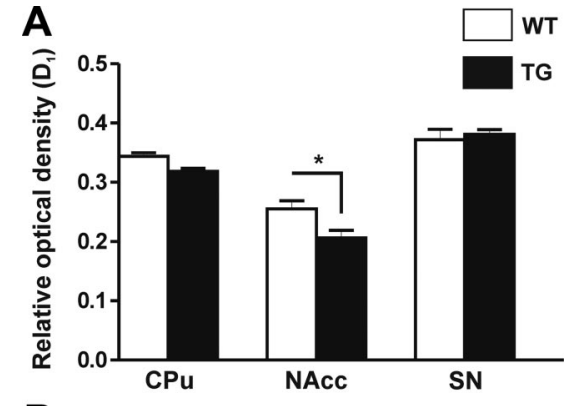

B

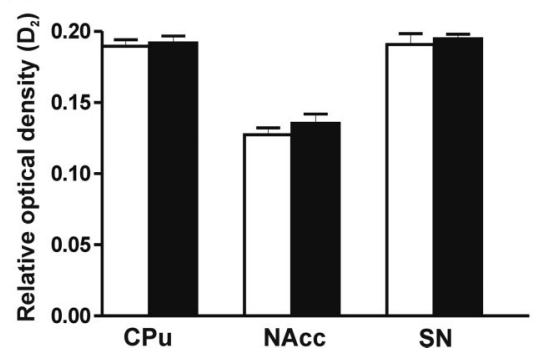

Figure 3. $D_{1} R$ and $D_{2} R$ ligand autoradiography. The brain sections were incubated with $\left[{ }^{3} \mathrm{H}\right] \mathrm{SCH} 23390$ (2 nм; $90 \mathrm{~min}$; room temperature) or [ $\left.{ }^{3} \mathrm{H}\right] \mathrm{YM}-09151$ (1 nм; $160 \mathrm{~min}$; room temperature) to assess $D_{1} R(\boldsymbol{A})$ or $D_{2} R(\boldsymbol{B})$ binding activity, respectively. For each animal, at least eight values of relative optical density (8 brain sections) were obtained. $n=8-11$ per group. ${ }^{*} p<0.05$ (two-way repeated ANOVA and Newman-Keuls post hoc test). Error bars indicate SEM.

tion under oxidative stress conditions. $\alpha$-Synuclein mRNA levels and its targeting miR-7b remained unchanged in the GFAP. HMOX1 mice at 6 weeks; however, the former were significantly elevated and the latter was highly suppressed $(p<0.001)$ in SN/VTA at 48 weeks relative to WT values (Fig. $4 F$ ). Compared with WT expression, miR-7b was reduced in the transgenic STM at 48 weeks $(p<0.05)$, but elevation of $\alpha$-synuclein mRNA did not achieve significance $(p>0.05)$. miR-7a expression in TG brain did not differ from control levels at the two ages tested (Fig. $4 F)$. $\alpha$-Synuclein protein was overexpressed and showed codis- tribution with HO-1 in the transgenic SN/VTA (Fig. 5C). Punctate ubiquitin immunoreactivity was more apparent in the transgenic STM and SN than in controls and may coregister with prominent deposits of mitochondrial iron noted within affected astroglia (W. Song, H. Zukor, and H. M. Schipper, unpublished observations). We last turned our attention to the expression of reelin, a neuronal and extracellular matrix glycoprotein with important roles in neuroembryogenesis and synaptic plasticity and which is substantially suppressed in the brains of persons with schizophrenia, bipolar disease, and AD (Knuesel, 2010). We observed a dramatic downregulation of immunoreactive reelin protein in and around neurons of the male transgenic PFC, $\mathrm{HC}, \mathrm{CPu}$ (Fig. 5F), and cerebellum (data not shown) compared with corresponding WT preparations. Female GFAP.HMOX1 mice displayed no discernible changes in neuronal reelin content in these brain regions relative to WT expression (Fig. $5 F$ ).

To complement ultrastructural evidence of mitophagy (above), the expression of several autophagy-related genes were analyzed. Becn 1 and Lamp2 mRNAs, markers of autophagy in injured astrocytes (Qin et al., 2010), were significantly increased in the transgenic SN/VTA at 48 weeks $(p<0.01$ and $p<0.05$, respectively) (Fig. $5 G$ ). The level/activity of sirt1, an $\mathrm{NAD}^{+}$. dependent deacetylase, is downregulated in cells exhibiting augmented autophagy in response to oxidative challenge (Hwang et al., 2010). We recently observed that the Sirt1 targeting miRNA, miR-138 is upregulated in HMOX1-transfected rodent astrocytes (our unpublished data). In the current study, Sirt1 mRNA levels were substantially diminished in the transgenic SN/VTA at 48 weeks of age ( $p<0.05$ vs control mice; Fig. $5 G)$. We also observed augmentation of LC3-II, a lipidated LC3 isoform and component of autophagosomes, in TG brains compared with WT preparations (Fig. $5 H$ ).

Neurovascular coupling is impaired in GFAP.HMOX1 mice Neurovascular coupling, a physiological property contingent on the integrity of neuronal-astroglial-microvascular communication, is attenuated in human neurodevelopmental and neurodegenerative disorders including schizophrenia (Ford et al., 2005) and AD (Pet- 
zold and Murthy, 2011). As calculated by percentage increase from baseline, the evoked cortical CBF response induced by whisker stimulation was significantly impaired in 12-week-old GFAP.HMOX1 mice $(7.72 \pm 1.58 \% ; n=5)$ in comparison with WT littermates $(13.97 \pm 1.51 \%$; $n=6$; $p<0.05$ ).

\section{Discussion}

Overexpression of HO-1 in astrocytes of GFAP.HMOX1 TG mice for 48 weeks resulted in a neuropathological profile characterized by oxidative stress, glial mitochondrial injury/autophagy; induction of Nurr 1 and Pitx3 associated with downregulation of their targeting miRNAs (133b and 145); increased TH, DAT, and $\alpha$-synuclein expression (with suppression of the targeting miR-7b of the latter); augmented basal ganglia DA and 5-HT levels; diminished $\mathrm{D}_{1} \mathrm{R}$ binding (nucleus accumbens); reduced neuronal reelin content (males); dentate gyrus dysgenesis; axodendritic damage; attenuated neurovascular coupling; impaired prepulse inhibition (males); and hyperkinetic behavior. The latter was not observed when expression of the transgene was constrained to the prepubertal or postpubertal periods. The neuritic damage, aberrant DA and 5-HT levels, and behavioral disturbances observed in GFAP.HMOX1 mice constitute direct evidence that profound neurochemical and neurodystrophic effects may be evoked by a primary insult to the astroglial compartment. This formulation is consistent with recent perception of astroglia as (1) a full partner, along with presynaptic and postsynaptic neurons, in the "tripartite synapse" (Perea et al., 2009) providing essential contributions to $\mathrm{Ca}^{2+}$ signaling networks, synaptogenesis, synaptic transmission, and gliotransmission (Haydon and Carmignoto, 2006); (2) a driver of neurological dysfunction as in the case of hyperammonemic encephalopathy (Brusilow et al., 2010), blood-brain barrier disruption (Krum, 1994), and chronic neuropathic pain syndromes (Hulsebosch, 2008); and (3) a legitimate target for therapeutic intervention (Schipper et al., 2009b). Involvement of ependymocytes and tanycytes in the GFAP.HMOX1 neurophenotype, albeit unlikely given the topography of the structural and biochemical lesions, cannot be entirely excluded as these cells express GFAP and the HMOX1 transgene.

The impaired prepulse inhibition and increased spontaneous horizontal movements and stereotypy observed in the GFAP. HMOX1 mice are behaviors common to many rodent models of neurodevelopmental (schizophrenia, autism, attention deficit/ hyperactivity disorder) and some neurodegenerative $(\mathrm{AD}, \mathrm{PD})$ conditions, elicited pharmacologically or by genetic manipulation. In the majority of cases, hyperdopaminergic tone in the nigrostriatal and mesolimbic systems is responsible for these abnormal behaviors (Viggiano, 2008). Hyperactivity and attenu-
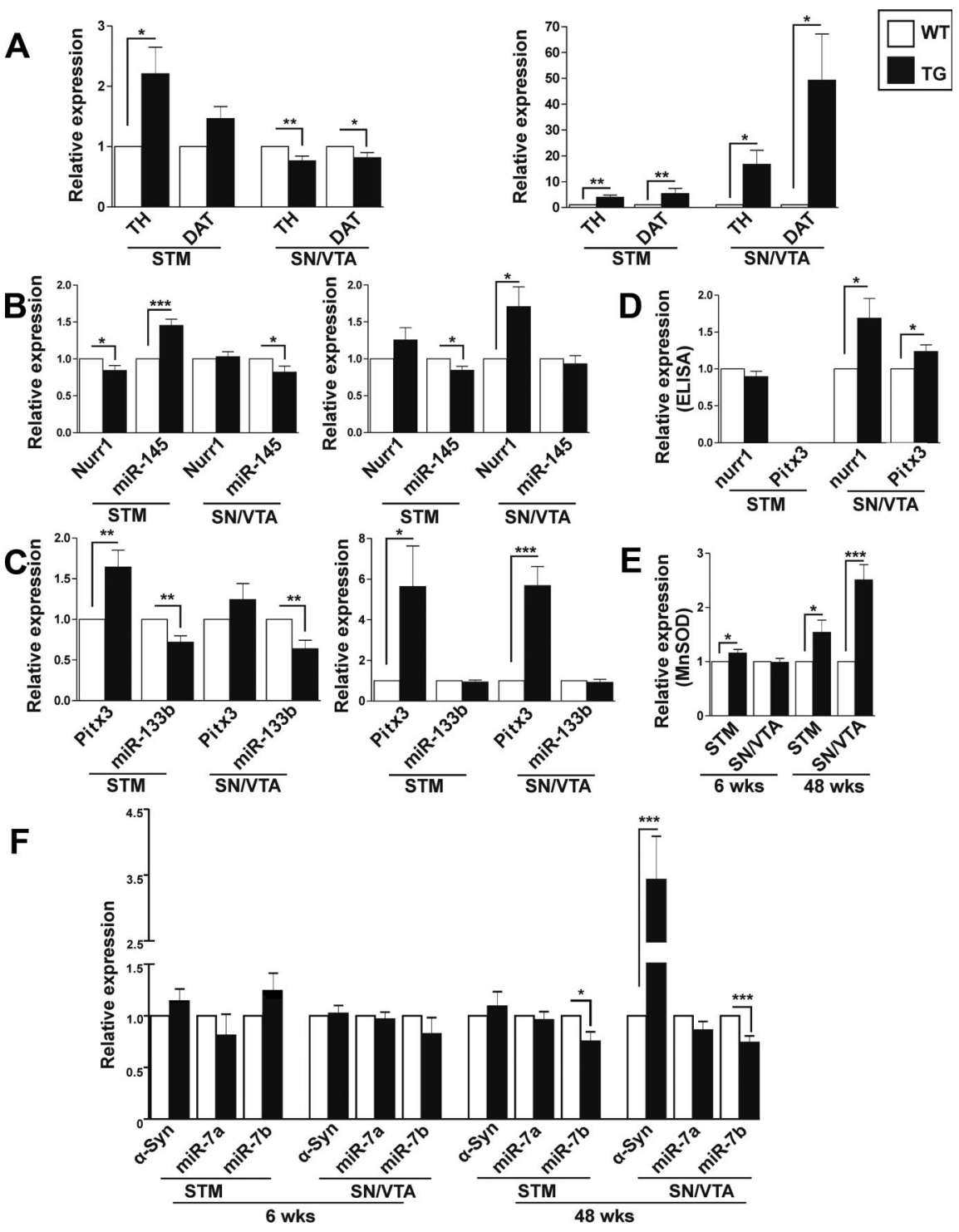

Figure 4. Brain gene expression profiles. mRNA levels for TH and DAT $(\boldsymbol{A}), \operatorname{Nurr1}(\boldsymbol{B}), \operatorname{Pitx} 3(\boldsymbol{C}), \operatorname{MnSOD}(\boldsymbol{E})$, and $\alpha$-Synuclein $(\boldsymbol{F})$, and miRNAs $145,133 \mathrm{~b}(\boldsymbol{B}, \boldsymbol{C})$, and $7 \mathrm{a} / \mathrm{b}(\boldsymbol{F})$ in GFAP.HMOX1 and WT brains were quantified by $q$ PCR at 6 weeks ( $\boldsymbol{A}-\boldsymbol{C}$, left panels) and 48 weeks $(\boldsymbol{A}-\boldsymbol{C}$, right panels). Brain nurr1 and pitx3 protein concentrations in 48-week-old TG and WT mice were measured by ELISA (D). $n=4-6$ per group. ${ }^{*} p<0.05 ;{ }^{* *} p<0.01 ;{ }^{* * *} p<0.001$. Error bars indicate SEM.

ated prepulse inhibition in GFAP.HMOX1 mice may similarly be due to robust increases in DA concentrations documented in substantia nigra and striatum. The latter likely result from enhanced expression of TH and DAT mRNA and protein in these brain regions. The registered induction of Nurrl and Pitx3, transcription factors required for dopamine synthesis/regulation and terminal differentiation/maintenance of dopaminergic neurons, respectively, would account for the upregulation of TH and DAT in these animals (Katunar et al., 2009). In turn, suppression of miR-133b (Kim et al., 2007) and miR-145 in the basal ganglia of GFAP.HMOX1 would explain the upregulation of Pitx 3 and Nurr 1 in the affected striatum and substantia nigra. Along similar lines, the increased brain $\alpha$-synuclein mRNA and protein levels noted may be secondary to the local suppression of miR-7 (Junn et al., 2009; Doxakis, 2010). The upregulation of HO-1 in astrocytes renders nearby neuronal constituents prone to oxidative stress (Schipper et al., 2009a), which, by downmodulating salient miRNAs (Dresios et al., 2005; Marsit et al., 2006), could promote 
A

B
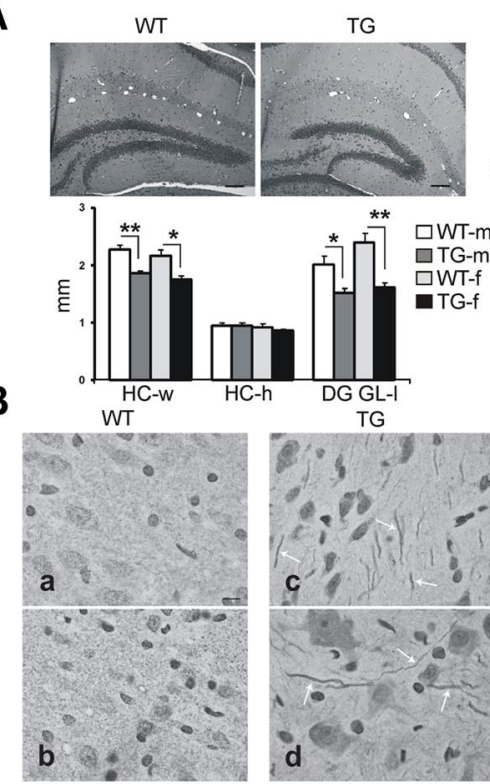

C

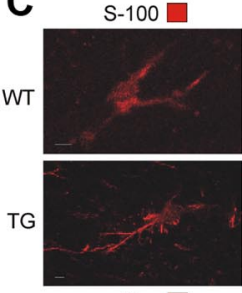

Flag $\square$

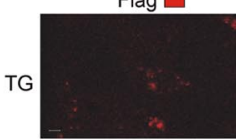

TH $\square$
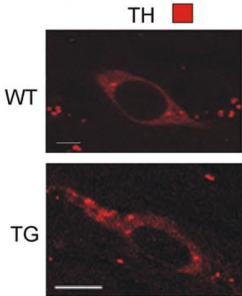

HO-1 $\square$


G

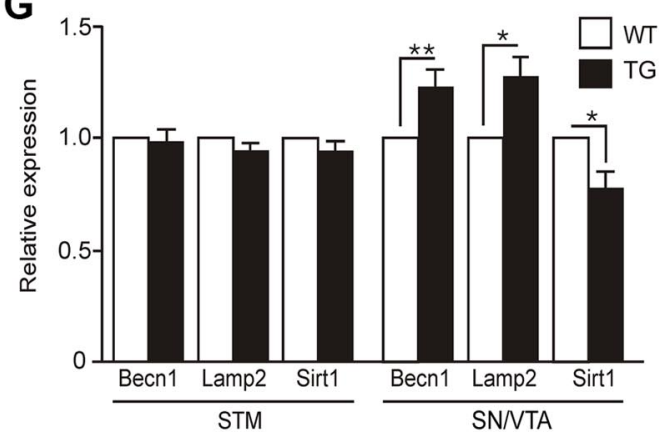

D

WT

.



E

Merge $\square$



MnSOD $\square$

Merge $\square$
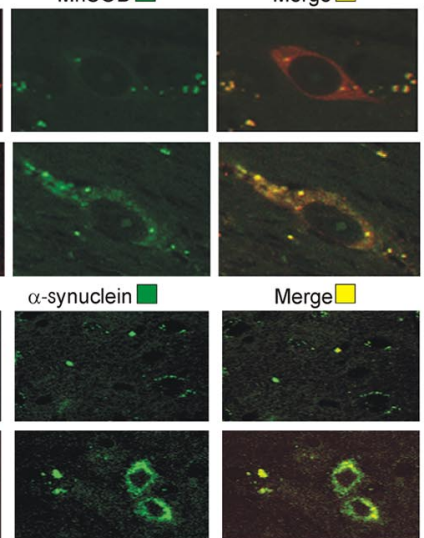

Merge $\square$


F

CPu

PFC
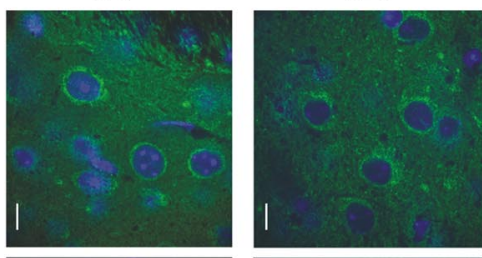

$\alpha$-synuclein $\square$
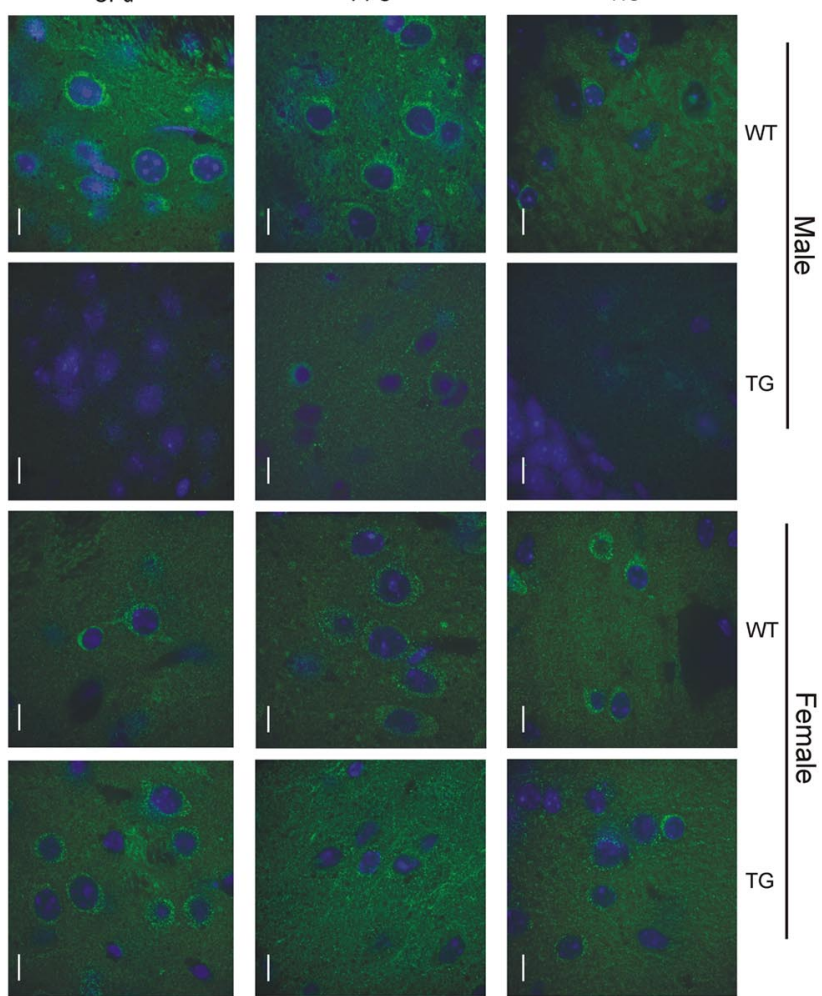

H
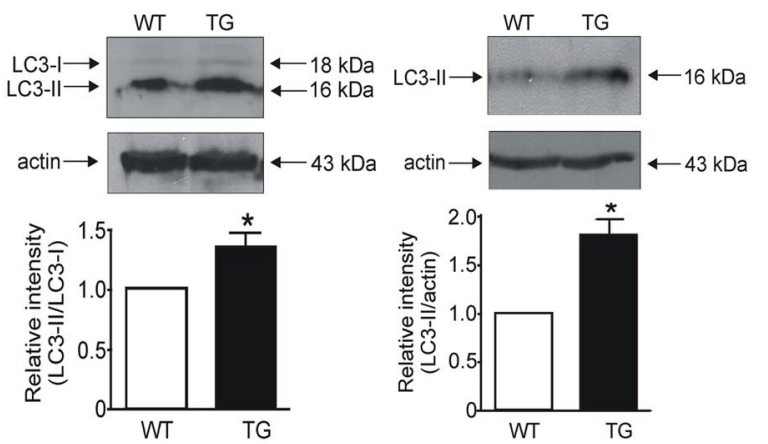

Figure 5. Neuropathology. Neurohistopathology data were derived from 48-week-old GFAP.HMOX1 and WT animals. A, (1) Dysgenesis of the hippocampal dentate gyrus in a male GFAP.HMOX1 mouse (H\&E stain) (top panels). Scale bars, $100 \mu \mathrm{m}$. (2) Morphometry of male $(\mathrm{m})$ and female (f) hippocampal width (w) and height ( $\mathrm{h}$ ), and the length (I) of the dentate (Figure legend continues.) 




Figure 6. "Transducer" model of astroglial H0-1 in chronic CNS disorders. In prenatal and early postnatal life (top), glial H0-1 acts as an epigenetic transducer of inimical influences on the establishment of monoaminergic circuitry comprising both neurodevelopmental and degenerative changes. Stressor induction of glial HMOX1 in later life (aging model; bottom) circumvents the developmental anomalies and engenders neurophenotypes that are exclusively degenerative in nature. See text (Discussion) for further details. The solid arrows indicate pathways supported by current data or literature. The hatched arrows denote conjectural mechanisms. $\mathrm{Fe}^{2+}$, ferrous iron; $\mathrm{GSH}$, glutathione; hippoc., hippocampus; NVC, neurovascular coupling; OS, oxidative stress.

overexuberant development of the dopaminergic system during neuroembryogenesis and subsequent hyperlocomotion.

The GFAP.HMOX1 mouse displays many characteristics commensurate with human schizophrenia including (1) hyper-

$\leftarrow$

(Figure legend continued.) gyrus granular layer (DG GL). $n=4$ (TG-m), 5 (WT-m), 4 (TG-f), 4 (WT-f). ${ }^{*} p<0.05$; ${ }^{* *} p<0.01$. Error bars indicate SEM. $\boldsymbol{B}$, Gallyas silver staining of coronal brain sections demonstrates abundant neuritic damage in the GFAP.HMOX1 SN (arrows, $\boldsymbol{c}, \boldsymbol{d}$ ) but not in respective WT $(\boldsymbol{a}, \boldsymbol{b})$ preparations. Scale bar, $10 \mu \mathrm{m}$. $\boldsymbol{C}$, MnSOD protein is overexpressed and colocalizes with S-100 $\beta$ (scale bar, $10 \mu \mathrm{m}$ ), Flag-H0-1 (scale bar, $20 \mu \mathrm{m}$ ), and TH (scale bar, $10 \mu \mathrm{m}$ ) in the transgenic SN (48 weeks). In the latter, $\alpha$-synuclein protein is also upregulated and codistributes with H0-1 (scale bars, $10 \mu \mathrm{m}$ ). D, GFAP.HMOX1 and WT brain ultrastructure. Fields depicted in $\boldsymbol{a}, \boldsymbol{c}, \boldsymbol{e}$, and $\boldsymbol{g}$ are shown at higher magnifications in $\boldsymbol{b}, \boldsymbol{d}, \boldsymbol{f}$, and $\boldsymbol{h}$, respectively. Astrocytes in wild-type SN $(\boldsymbol{a}, \boldsymbol{b})$ and AMYG $(\boldsymbol{c}, \boldsymbol{d})$ exhibit normal euchromatic nuclei $(\mathrm{N})$ and mitochondria (white arrows) and few or no pathological inclusions. Astrocytes in the transgenic SN $(\boldsymbol{e}, \boldsymbol{f})$ and AMYG $(\boldsymbol{g}, \boldsymbol{h})$ contain distended mitochondria with disorganized cristae (black arrows), osmiophilic cytoplasmic inclusions (arrowheads), and frequent nuclear envelope invaginations (asterisks). $\boldsymbol{E}$, Transgenic astrocytes exhibit lipofuscin granules (arrowhead) infrequently encountered in WT cells at this age. Degenerate neurites are observed in close proximity to pathological astrocytes in TG, but not WT, brains (curved arrows). $\boldsymbol{F}$, Neuronal reelin immunoreactivity is markedly reduced in the male transgenic $\mathrm{HC}$, PFC, and CPu compared with WT littermates. Female transgenic mice displayed no significant changes of neuronal reelin content in the corresponding regions relative to WT preparations. Scale bar, $10 \mu \mathrm{m}$. G, mRNA levels for Becn1, Lamp2, and Sirt1 in GFAP.HMOX1 and WT brains were quantified by qPCR. $n=4-6$ for each group. ${ }^{*} p<0.05 ;{ }^{* *} p<0.01$. $\boldsymbol{H}$, Western blots and densitometry for LC3-I/II expression in whole-cell lysates (left panels) and membrane fractions (right panels) in wild-type and transgenic AMYG. Only LC3-II was detected in membrane fractions. $n=4$ per group. ${ }^{*} p<0.05$. kinesias (Ungvari et al., 2009), (2) attenuated prepulse inhibition that is typically more evident in men (Aasen et al., 2005), (3) hyperdopaminergia (Meisenzahl et al., 2007; Howes and Kapur, 2009) without accelerated DA turnover (Post et al., 1975; van Kammen et al., 1986; Beuger et al., 1996), (4) diminished $\mathrm{D}_{1}$ receptor binding [prefrontal cortex in schizophrenia (Okubo et al., 1997); nucleus accumbens in our mice], (5) increased basal ganglia serotonin levels (Korpi et al., 1986), (6) altered hippocampal cytoarchitectonics (Jakob and Beckmann, 1986; Scheibel and Conrad, 1993), (7) decreased neuronal reelin content (Knuesel, 2010), (8) increased brain $\alpha$-synuclein expression (Pennington et al., 2008), (9) CNS oxidative stress (Prabakaran et al., 2004), (10) delayed hemodynamic responses (Ford et al., 2005), (11) altered brain sterol metabolism (Horrobin et al., 1991) (J. Hascalovici and H. M. Schipper, unpublished results), and, central to our thesis, (12) upregulation of HO-1 in affected neural tissues (Prabakaran et al., 2004), and (13) astroglial mitochondrial damage and autophagy (Prabakaran et al., 2004; Kolomeets and Uranova, 2010). The GFAP.HMOX1 mice also exhibit enhanced astroglial iron deposition (W. Song, H. Zukor, and H. M. Schipper, unpublished observations) akin to earlier observations in HMOX1-transfected glial cultures (Zukor et al., 2009). However, the relevance of this finding to schizophrenia is difficult to gauge in light of controversy whether increases in brain iron reported in human schizophrenia are due to the disease or exposure to neuroleptic medications (Casanova et al., 1992). The absence of astroglial hypertrophy (evidenced by nor- 
mal GFAP and S- $100 \beta$ mRNA and protein levels) is not surprising given that glial HMOX1 expression in our model yields a predominantly neurodevelopmental phenotype. The lack of overt gliosis in human schizophrenic brain and other early-life CNS conditions has similarly been adduced as evidence favoring developmental, in contradistinction to degenerative, neuropathology (Roberts et al., 1987; Cotter et al., 2001). To the extent that the GFAP.HMOX1 mouse recapitulates neurochemical aspects of human schizophrenia, our findings of unaltered brain glutamate levels may argue against the hypothesis that aberrant glutamatergic transmission is fundamental to the pathophysiology of hyperkinesia in the disease (Grace, 2000).

As a potential model of schizophrenia, the GFAP.HMOX1 mouse has several limitations: (1) There is no single animal model that fully recapitulates human schizophrenia, given the complexity of the disorder and the restricted homology between animal and human CNSs. Although the GFAP.HMOX1 mouse appears to capture numerous "positive" characteristics of the human disease (hyperlocomotion, stereotypy, aberrant PPI, etc.), "negative" symptoms such as blunted affect and social withdrawal remain to be demonstrated. (2) The endpoints were sampled at limited intervals so the precise sequence of pathologic events downstream of glial HMOX1 expression that culminate in the observed neurophenotype cannot be determined with certainty at this juncture. However, the cascade of events schematized in Figure 6 is fully consistent with the data garnered and provides a logical and parsimonious working model to guide further study.

A host of prenatal and early postnatal stressors have been implicated as risk factors or triggers for human neurodevelopmental disorders such as autism, schizophrenia, and attention deficit/hyperactivity disorder. In the case of schizophrenia, candidate perinatal stressors include maternal psychotrauma and hypothalamic-pituitary-adrenal activation, pregnant exposure to noxious chemicals, and maternal infection (bacterial, viral, or parasitic) (King et al., 2010; Brown, 2011). Maternal infection is associated with immune activation and elaboration of proinflammatory cytokines that may mediate dystrophic effects within the developing neuraxis (Shi et al., 2003; Ozawa et al., 2006; Fortier et al., 2007; Meyer et al., 2008). A panoply of consensus sequences within the HMOX1 promoter render the gene sensitive to upregulation by proinflammatory cytokines, lipopolysaccharide, and other stressors (Schipper et al., 2009a) implicated in the development of schizophrenia (Brown, 2011). The GFAP.HMOX1 mouse teaches that sustained or repeated induction of HO-1 in brain astrocytes may be a critical link in the etiopathogenesis of schizophrenia and other neurodevelopmental disorders by transducing the deleterious influences of various perinatal stressors into altered patterns of dopaminergic cell development in the immature subcortex. Our findings suggest further that enhanced Nurr1 and Pitx3 expression recently reported in the brains of prenatally stressed adult rats (Katunar et al., 2009) may have been contingent on the antecedent upregulation of $\mathrm{HO}-1$ in exposed astroglia. As postulated for human schizophrenia (Grace, 2000), a prenatal window of astroglial stress appears necessary for the delayed emergence of DA-dependent hyperlocomotion in our model because the latter did not materialize when glial expression of the HMOX1 transgene was selectively repressed by Dox in the prepubertal period.

Conceivably, perinatal stressors activating the astrocytic HO- 1 cascade before the maturation of mesolimbic and nigrostriatal pathways induce "hypertrophy" of dopaminergic circuitry and neurodegenerative changes culminating as a neurodevelopmental hyperkinesia (e.g., schizophrenia) in early adulthood (Fig. 6), whereas homologous influences acting upon established dopaminergic projections later in life may yield phenotypes that are purely degenerative in nature (e.g., PD) (Schipper et al., 2009a). The suppression of neuronal reelin content observed in the male GFAP.HMOX1 mice may be particularly germane in this regard. Reelin is a conserved glycoprotein crucial for normal neuronal migration, differentiation, and corticogenesis in the developing mammalian brain. In the adult CNS, reelin-dependent signaling is an important modulator of NMDA receptormediated neurotransmission required for synaptic plasticity, learning, and memory (Knuesel, 2010). Thus, stressor/HO-1induced curtailment of reelin action might precipitate neurodevelopmental anomalies (e.g., neuropil hypoplasia, hippocampal dysgenesis, and impaired PPI) (Stanfield and Cowan, 1979; Liu et al., 2001) when operational prenatally and perinatally, whereas exclusively neurodegenerative phenotypes (e.g., AD, PD) may accrue from sustained or repeated activation of this axis in the mature brain.

Several important sex-specific disparities were apparent in the GFAP.HMOX1 mice. Suppressed neuronal reelin expression and impaired PPI were unique to the males, whereas the other documented abnormalities were common to both sexes. These findings are reminiscent of gender-associated differences in PPI and other endophenotypes of human schizophrenia (Aasen et al., 2005). Moreover, our findings suggest that (1) hyperdopaminergia alone may be insufficient to compromise PPI in the face of normal reelin expression and (2) astroglial induction of HMOX1 may drive hippocampal dysgenesis and axodendritic damage independently of alterations in reelin content (Fig. 6). Our observations in the GFAP.HMOX1 mouse recapitulate with high fidelity many cytopathological features accruing from the overexpression of HO-1 in primary glial culture. Moreover, the current data cast glial HMOX1 induction as a vital epigenetic transducer of noxious stimuli in a potentially broad spectrum of chronic CNS conditions. In this regard, containment of the glial HO-1 response at strategic points of the life course by pharmacological or other means may afford novel opportunities for the effective management (primary and secondary prevention) of human neurodevelopmental and neurodegenerative disorders.

\section{Notes}

Supplemental material for this article is available at www.ladydavis.ca/ en/hymanschipper. The videoclips demonstrate robust spontaneous circling behavior (stereotypy) in a 48-week-old GFAP.HMOX1 transgenic mouse that is not observed in an age-matched WT control animal. The videos were recorded at the Neurophenotyping Centre of the Douglas Mental Health University Institute (McGill University, Montreal, Quebec, Canada). This material has not been peer reviewed.

\section{References}

Aasen I, Kolli L, Kumari V (2005) Sex effects in prepulse inhibition and facilitation of the acoustic startle response: implications for pharmacological and treatment studies. J Psychopharmacol 19:39-45.

Ahmad AS, Zhuang H, Doré S (2006) Heme oxygenase-1 protects brain from acute excitotoxicity. Neuroscience 141:1703-1708.

Beschorner R, Adjodah D, Schwab JM, Mittelbronn M, Pedal I, Mattern R, Schluesener HJ, Meyermann R (2000) Long-term expression of heme oxygenase-1 (HO-1, HSP-32) following focal cerebral infarctions and traumatic brain injury in humans. Acta Neuropathol 100:377-384.

Beuger M, van Kammen DP, Kelley ME, Yao J (1996) Dopamine turnover in schizophrenia before and after haloperidol withdrawal. CSF, plasma, and urine studies. Neuropsychopharmacology 15:75-86.

Brown AS (2011) The environment and susceptibility to schizophrenia. Prog Neurobiol 93:23-58.

Brusilow SW, Koehler RC, Traystman RJ, Cooper AJ (2010) Astrocyte glu- 
tamine synthetase: importance in hyperammonemic syndromes and potential target for therapy. Neurotherapeutics 7:452-470.

Casanova MF, Comparini SO, Kim RW, Kleinman JE (1992) Staining intensity of brain iron in patients with schizophrenia: a postmortem study. J Neuropsychiatry Clin Neurosci 4:36-41.

Cotter DR, Pariante CM, Everall IP (2001) Glial cell abnormalities in major psychiatric disorders: the evidence and implications. Brain Res Bull 55:585-595.

Doxakis E (2010) Post-transcriptional regulation of alpha-synuclein expression by mir-7 and mir-153. J Biol Chem 285:12726-12734.

Dresios J, Aschrafi A, Owens GC, Vanderklish PW, Edelman GM, Mauro VP (2005) Cold stress-induced protein Rbm 3 binds 60 S ribosomal subunits, alters microRNA levels, and enhances global protein synthesis. Proc Natl Acad Sci U S A 102:1865-1870.

Fenton H, Finch PW, Rubin JS, Rosenberg JM, Taylor WG, Kuo-Leblanc V, Rodriguez-Wolf M, Baird A, Schipper HM, Stopa EG (1998) Hepatocyte growth factor (HGF/SF) in Alzheimer's disease. Brain Res 779:262-270.

Fernandez-Gonzalez A, Pérez-Otaño I, Morgan JI (2000) MPTP selectively induces haem oxygenase-1 expression in striatal astrocytes. Eur J Neurosci 12:1573-1583.

Ford JM, Johnson MB, Whitfield SL, Faustman WO, Mathalon DH (2005) Delayed hemodynamic responses in schizophrenia. Neuroimage 26:922-931.

Fortier ME, Luheshi GN, Boksa P (2007) Effects of prenatal infection on prepulse inhibition in the rat depend on the nature of the infectious agent and the stage of pregnancy. Behav Brain Res 181:270-277.

Frankel D, Schipper HM (1999) Cysteamine pretreatment of the astroglial substratum (mitochondrial iron sequestration) enhances PC12 cell vulnerability to oxidative injury. Exp Neurol 160:376-385.

Frankel D, Mehindate K, Schipper HM (2000) Role of heme oxygenase-1 in the regulation of manganese superoxide dismutase gene expression in oxidatively-challenged astroglia. J Cell Physiol 185:80-86.

Gains MJ, Roth KA, LeBlanc AC (2006) Prion protein protects against ethanol-induced Bax-mediated cell death in vivo. Neuroreport 17:903-906.

Grace AA (2000) Gating of information flow within the limbic system and the pathophysiology of schizophrenia. Brain Res Brain Res Rev 31:330-341.

Gratton A, Hoffer BJ, Gerhardt GA (1989) In vivo electrochemical studies of monoamine release in the medial prefrontal cortex of the rat. Neuroscience 29:57-64.

Haydon PG, Carmignoto G (2006) Astrocyte control of synaptic transmission and neurovascular coupling. Physiol Rev 86:1009-1031.

Horrobin DF, Manku MS, Hillman H, Iain A, Glen M (1991) Fatty acid levels in the brains of schizophrenics and normal controls. Biol Psychiatry 30:795-805.

Howes OD, Kapur S (2009) The dopamine hypothesis of schizophrenia: version III-the final common pathway. Schizophr Bull 35:549-562.

Hulsebosch CE (2008) Gliopathy ensures persistent inflammation and chronic pain after spinal cord injury. Exp Neurol 214:6-9.

Hwang JW, Chung S, Sundar IK, Yao H, Arunachalam G, McBurney MW, Rahman I (2010) Cigarette smoke-induced autophagy is regulated by SIRT1-PARP-1-dependent mechanism: implication in pathogenesis of COPD. Arch Biochem Biophys 500:203-209.

Jakob H, Beckmann H (1986) Prenatal developmental disturbances in the limbic allocortex in schizophrenics. J Neural Transm 65:303-326.

Junn E, Lee KW, Jeong BS, Chan TW, Im JY, Mouradian MM (2009) Repression of alpha-synuclein expression and toxicity by microRNA-7. Proc Natl Acad Sci U S A 106:13052-13057.

Katunar MR, Saez T, Brusco A, Antonelli MC (2009) Immunocytochemical expression of dopamine-related transcription factors Pitx3 and Nurr1 in prenatally stressed adult rats. J Neurosci Res 87:1014-1022.

Kim J, Inoue K, Ishii J, Vanti WB, Voronov SV, Murchison E, Hannon G, Abeliovich A (2007) A microRNA feedback circuit in midbrain dopamine neurons. Science 317:1220-1224.

King S, St-Hilaire A, Heidkamp D (2010) Prenatal factors in schizophrenia. Curr Dir Psychol Sci 19:209-213.

Knuesel I (2010) Reelin-mediated signaling in neuropsychiatric and neurodegenerative diseases. Prog Neurobiol 91:257-274.

Kolomeets NS, Uranova N (2010) Ultrastructural abnormalities of astro- cytes in the hippocampus in schizophrenia and duration of illness: a postortem morphometric study. World J Biol Psychiatry 11:282-292.

Korpi ER, Kleinman JE, Goodman SI, Phillips I, DeLisi LE, Linnoila M, Wyatt RJ (1986) Serotonin and 5-hydroxyindoleacetic acid in brains of suicide victims. Comparison in chronic schizophrenic patients with suicide as cause of death. Arch Gen Psychiatry 43:594-600.

Krum JM (1994) Experimental gliopathy in the adult rat CNS: effect on the blood-spinal cord barrier. Glia 11:354-366.

Laplante F, Srivastava LK, Quirion R (2004) Alterations in dopaminergic modulation of prefrontal cortical acetylcholine release in postpubertal rats with neonatal ventral hippocampal lesions. J Neurochem 89:314-323.

Li Y, Hu J, Höfer K, Wong AM, Cooper JD, Birnbaum SG, Hammer RE, Hofmann SL (2010) DHHC5 interacts with PDZ domain 3 of postsynaptic density-95 (PSD-95) protein and plays a role in learning and memory. J Biol Chem 285:13022-13031.

Lin Y, Vreman HJ, Wong RJ, Tjoa T, Yamauchi T, Noble-Haeusslein LJ (2007) Heme oxygenase-1 stabilizes the blood-spinal cord barrier and limits oxidative stress and white matter damage in the acutely injured murine spinal cord. J Cereb Blood Flow Metab 27:1010-1021.

Liu WS, Pesold C, Rodriguez MA, Carboni G, Auta J, Lacor P, Larson J, Condie BG, Guidotti A, Costa E (2001) Down-regulation of dendritic spine and glutamic acid decarboxylase 67 expressions in the reelin haploinsufficient heterozygous reeler mouse. Proc Natl Acad Sci U S A 98:3477-3482.

Livak KJ, Schmittgen TD (2001) Analysis of relative gene expression data using real-time quantitative PCR and the $2^{-\Delta \Delta C(\mathrm{~T})}$ method. Methods 25:402-408.

Mak SK, McCormack AL, Langston JW, Kordower JH, Di Monte DA (2009) Decreased alpha-synuclein expression in the aging mouse substantia nigra. Exp Neurol 220:359-365.

Marsit CJ, Eddy K, Kelsey KT (2006) MicroRNA responses to cellular stress. Cancer Res 66:10843-10848.

Meisenzahl EM, Schmitt GJ, Scheuerecker J, Möller HJ (2007) The role of dopamine for the pathophysiology of schizophrenia. Int Rev Psychiatry 19:337-345.

Meyer U, Engler A, Weber L, Schedlowski M, Feldon J (2008) Preliminary evidence for a modulation of fetal dopaminergic development by maternal immune activation during pregnancy. Neuroscience 154:701-709.

Naef L, Srivastava L, Gratton A, Hendrickson H, Owens SM, Walker CD (2008) Maternal high fat diet during the perinatal period alters mesocorticolimbic dopamine in the adult rat offspring: reduction in the behavioral responses to repeated amphetamine administration. Psychopharmacology (Berl) 197:83-94.

Nitta H, Kinoyama M, Watanabe A, Fujita Y, Ueda H, Shirao K (2007) Measurement of carbon monoxide in exhaled breath as a possible marker of stress. J Health Sci 53:132-136.

Okubo Y, Suhara T, Suzuki K, Kobayashi K, Inoue O, Terasaki O, Someya Y, Sassa T, Sudo Y, Matsushima E, Iyo M, Tateno Y, Toru M (1997) Decreased prefrontal dopamine $\mathrm{D}_{1}$ receptors in schizophrenia revealed by PET. Nature 385:634-636.

Ozawa K, Hashimoto K, Kishimoto T, Shimizu E, Ishikura H, Iyo M (2006) Immune activation during pregnancy in mice leads to dopaminergic hyperfunction and cognitive impairment in the offspring: a neurodevelopmental animal model of schizophrenia. Biol Psychiatry 59:546-554.

Panahian N, Yoshiura M, Maines MD (1999) Overexpression of heme oxygenase-1 is neuroprotective in a model of permanent middle cerebral artery occlusion in transgenic mice. J Neurochem 72:1187-1203.

Patterson C, Feightner J, Garcia A, MacKnight C (2007) General risk factors for dementia: a systematic evidence review. Alzheimers Dement 3:341-347.

Pennington K, Dicker P, Dunn MJ, Cotter DR (2008) Proteomic analysis reveals protein changes within layer 2 of the insular cortex in schizophrenia. Proteomics 8:5097-5107.

Perea G, Navarrete M, Araque A (2009) Tripartite synapses: astrocytes process and control synaptic information. Trends Neurosci 32:421-431.

Petzold GC, Murthy VN (2011) Role of astrocytes in neurovascular coupling. Neuron 71:782-797.

Pinna G, Agis-Balboa RC, Zhubi A, Matsumoto K, Grayson DR, Costa E, Guidotti A (2006) Imidazenil and diazepam increase locomotor activity in mice exposed to protracted social isolation. Proc Natl Acad Sci U S A 103:4275-4280. 
Post RM, Fink E, Carpenter WT Jr, Goodwin FK (1975) Cerebrospinal fluid amine metabolites in acute schizophrenia. Arch Gen Psychiatry 32:1063-1069.

Prabakaran S, Swatton JE, Ryan MM, Huffaker SJ, Huang JT, Griffin JL, Wayland M, Freeman T, Dudbridge F, Lilley KS, Karp NA, Hester S, Tkachev D, Mimmack ML, Yolken RH, Webster MJ, Torrey EF, Bahn S (2004) Mitochondrial dysfunction in schizophrenia: evidence for compromised brain metabolism and oxidative stress. Mol Psychiatry 9:684697, 643.

Preisig-Müller R, Mederos y Schnitzler M, Derst C, Daut J (1999) Separation of cardiomyocytes and coronary endothelial cells for cell-specific RT-PCR. Am J Physiol 277:H413-H416.

Premkumar DR, Smith MA, Richey PL, Petersen RB, Castellani R, Kutty RK, Wiggert B, Perry G, Kalaria RN (1995) Induction of heme oxygenase-1 mRNA and protein in neocortex and cerebral vessels in Alzheimer's disease. J Neurochem 65:1399-1402.

Qin AP, Liu CF, Qin YY, Hong LZ, Xu M, Yang L, Liu J, Qin ZH, Zhang HL (2010) Autophagy was activated in injured astrocytes and mildly decreased cell survival following glucose and oxygen deprivation and focal cerebral ischemia. Autophagy 6:738-753.

Roberts GW, Colter N, Lofthouse R, Johnstone EC, Crow TJ (1987) Is there gliosis in schizophrenia? Investigation of the temporal lobe. Biol Psychiatry 22:1459-1468.

Scheibel AB, Conrad AS (1993) Hippocampal dysgenesis in mutant mouse and schizophrenic man: is there a relationship? Schizophr Bull 19:21-33.

Schipper HM (1999) Glial HO-1 expression, iron deposition and oxidative stress in neurodegenerative diseases. Neurotox Res 1:57-70.

Schipper HM, Cissé S, Stopa EG (1995) Expression of heme oxygenase-1 in the senescent and Alzheimer-diseased brain. Ann Neurol 37:758-768.

Schipper HM, Liberman A, Stopa EG (1998) Neural heme oxygenase-1 expression in idiopathic Parkinson's disease. Exp Neurol 150:60-68.

Schipper HM, Song W, Zukor H, Hascalovici JR, Zeligman D (2009a) Heme oxygenase- 1 and neurodegeneration: expanding frontiers of engagement. J Neurochem 110:469-485.

Schipper HM, Gupta A, Szarek WA (2009b) Suppression of glial HO-1 activity as a potential neurotherapeutic intervention in $\mathrm{AD}$. Curr Alzheimer Res 6:424-430.

Shi L, Fatemi SH, Sidwell RW, Patterson PH (2003) Maternal influenza infection causes marked behavioral and pharmacological changes in the offspring. J Neurosci 23:297-302.

Smith MA, Kutty RK, Richey PL, Yan SD, Stern D, Chader GJ, Wiggert B, Petersen RB, Perry G (1994) Heme oxygenase-1 is associated with the neurofibrillary pathology of Alzheimer's disease. Am J Pathol 145:42-47.

Song L, Song W, Schipper HM (2007) Astroglia overexpressing heme oxygenase-1 predispose co-cultured PC12 cells to oxidative injury. J Neurosci Res 85:2186-2195.

Song W, Su H, Song S, Paudel HK, Schipper HM (2006) Over-expression of heme oxygenase-1 promotes oxidative mitochondrial damage in rat astroglia. J Cell Physiol 206:655-663.

Song W, Patel A, Qureshi HY, Han D, Schipper HM, Paudel HK (2009) The Parkinson disease-associated A30P mutation stabilizes alpha-synuclein against proteasomal degradation triggered by heme oxygenase- 1 overexpression in human neuroblastoma cells. J Neurochem 110:719-733.

Stanfield BB, Cowan WM (1979) The morphology of the hippocampus and dentate gyrus in normal and reeler mice. J Comp Neurol 185:393-422.

Tong XK, Nicolakakis N, Fernandes P, Ongali B, Brouillette J, Quirion R, Hamel E (2009) Simvastatin improves cerebrovascular function and counters soluble amyloid-beta, inflammation and oxidative stress in aged APP mice. Neurobiol Dis 35:406-414.

Ungvari GS, Goggins W, Leung SK, Lee E, Gerevich J (2009) Schizophrenia with prominent catatonic features ("catatonic schizophrenia") III. Latent class analysis of the catatonic syndrome. Prog Neuropsychopharmacol Biol Psychiatry 33:81-85.

van Kammen DP, van Kammen WB, Mann LS, Seppala T, Linnoila M (1986) Dopamine metabolism in the cerebrospinal fluid of drug-free schizophrenic patients with and without cortical atrophy. Arch Gen Psychiatry 43:978-983.

Viggiano D (2008) The hyperactive syndrome: metanalysis of genetic alterations, pharmacological treatments and brain lesions which increase locomotor activity. Behav Brain Res 194:1-14.

Wang J, Doré S (2007) Heme oxygenase-1 exacerbates early brain injury after intracerebral haemorrhage. Brain 130:1643-1652.

Wong AA, Brown RE (2007) Age-related changes in visual acuity, learning and memory in C57BL/6J and DBA/2J mice. Neurobiol Aging 28:1577-1593

Wood GK, Tomasiewicz H, Rutishauser U, Magnuson T, Quirion R, Rochford J, Srivastava LK (1998) NCAM-180 knockout mice display increased lateral ventricle size and reduced prepulse inhibition of startle. Neuroreport 9:461-466.

Yuan Y, Guo JZ, Zhou QX (2008) The homeostasis of iron and suppression of HO-1 involved in the protective effects of nimodipine on neurodegeneration induced by aluminum overloading in mice. Eur J Pharmacol 586:100-105.

Zhang J, Piantadosi CA (1992) Mitochondrial oxidative stress after carbon monoxide hypoxia in the rat brain. J Clin Invest 90:1193-1199.

Zukor H, Song W, Liberman A, Mui J, Vali H, Fillebeen C, Pantopoulos K, Wu TD, Guerquin-Kern JL, Schipper HM (2009) HO-1-mediated macroautophagy: a mechanism for unregulated iron deposition in aging and degenerating neural tissues. J Neurochem 109:776-791. 